\title{
Growth Period (1954-1994): Maps Displaying More Information and Printed in More Standard Way
}

\author{
Liqiong Jia, Zhaoyu Kong, Xuezheng Gao, Hui Guo, \\ Xiaolei $\mathrm{Li}$, and Chunzhen He
}

With the rapid development of national construction and geological work, from 1953 to 1956, the state set up four Sino-Soviet cooperation regional geological survey brigades (Xinjiang 13th geological brigade, Daxing' anling geological brigade, Qinling geological brigade, and Nanling geological brigade). The General Survey Notes, compiled by Huang Jiqing and Xie Jiarong in 1954, put forward unified requirements for stratigraphic division, use of geological codes, various pattern symbols, and color marks in field mapping, thus providing scientific basis for unified representation of large-scale geological maps in China. Through Sino-Soviet cooperation and the unremitting efforts of our geological predecessors, a new situation has been opened up for the regional geological survey and geological mapping in China.

During this period, China's geological mapping has developed rapidly, and at the same time it enjoys a lot of international reputation. For example, from 1973 to 1976, the Geological Map of Asia (1:5 million), compiled by Li Tingdong, Li Chunyu, and Wang Hongzhen, and the Geological Map of the People's Republic of China (1:4 million), compiled by Geng Shufang, caused a great sensation when they participated in the 25th International Geological Congress exhibition, which was highly praised by foreign media.

China's geological mapping have developed to a more systematic and perfect stage. Geological map information is more rich and diverse, and the printing is more standardized. The relevant thematic studies are carried out simultaneously, such as agricultural ecological geology, environmental geology and tourism geology. The unified specific requirements of the representation method of geological maps, the shape, size, color, and structure of symbols, as well as the schema and legend, create conditions for the rapid transmission of geological information and automatic mapping.

L. Jia $(\bowtie) \cdot$ Z. Kong $\cdot$ X. Gao $\cdot$ H. Guo $\cdot$ X. Li $\cdot$ C. He Development and Research Center of China Geological Survey (National Geological Archives of China),

Xicheng District, Beijing, P.R. China
This monochromatic drawing has been meticulously done, with such fine attention to detail that even the houses behind the trees are accurately depicted. Mt. Shirenfeng is rendered using the simple wrinkled-texture method of traditional Chinese painting. Coupled with the clouds in background, this approach makes the picture both realistic and imaginative. The drawing's composition resembles that of a Tai Chi map, full of conflict and harmony (Fig. 4.1).

The measured layout and accurate rendition has high aesthetic quality. The vigorous lines seem dense enough to block the wind and recall the poetic thought that "The cloud wishes it were a bird" (Figs. 4.2 and 4.3).

Overall, the diagram adopts a triangular format, with a strong sense of perspective. The diagram is vertical, orderly, and lively (Fig. 4.7).

The macroscopic geological terrain is depicted with fine, artistic lines, such that the sketch resembles an elegant landscape painting. Depicting the local landscape in an objective, detailed manner, the sketch adds dramatic effects through a background of towering mountains and streaming clouds (Fig. 4.10).

The drawing is beautiful, with water in the foreground and mountains in the background in a movement from the dynamic to the static. The floating clouds add life to the quiet loftiness of the mountains while making the image more transparent, like a majestic perspective in oil painting. The drawing perfectly combines geology and aesthetics (Fig. 4.17).

The microscopic illustrations were drawn with colored pencils and are bright and succinct (Fig. 4.18).

The ore bodies in the diagram were drawn in orderly alignment and bright, contrasting colors. They are highlighted with geographical signs (Fig. 4.19).

The diagram is drawn in complex but clear lines combined with watercolor blocks and represents an engineering geological chart of a mining area in Guangdong Province (Fig. 4.20). 
Fig. 4.1 Geomorphological sketch of Shirenfeng tungsten mine, Shixing, Guangdong

Province (sheet 1) [1]
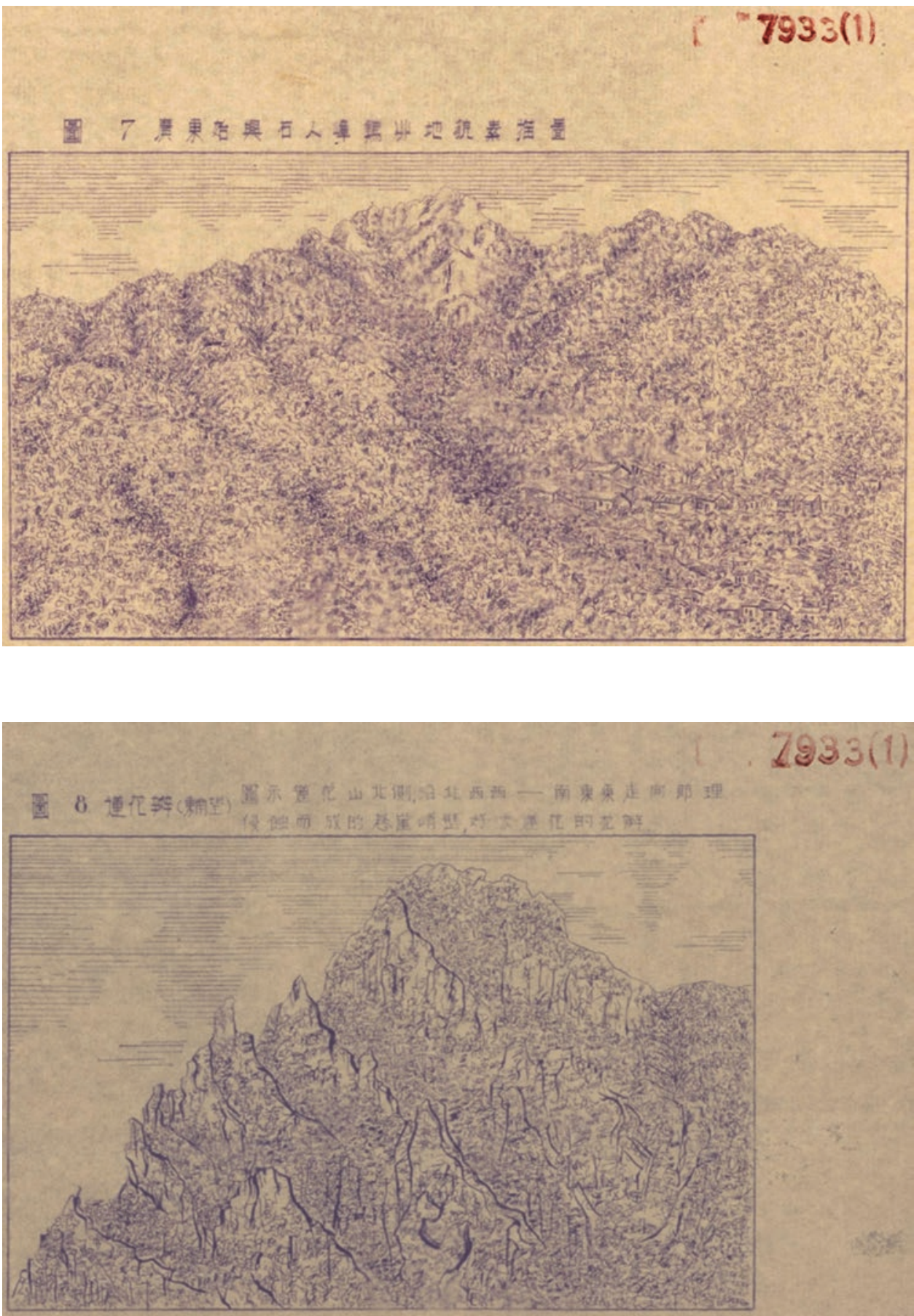

Fig. 4.2 Geomorphological sketch of Shirenfeng tungsten mine, Shixing, Guangdong (sheet 1) [2]
The creation of the 13th Sino-Soviet Geological Cooperation Brigade of Xinjiang in 1953 opened a new chapter in China's regional geological survey activity. The geological maps produced during this period are mostly bilingual in Chinese and Russian (Figs. 4.21 and 4.22).

This diagram describes the core preservation in solid figure (Fig. 4.23).

Lines and gouache coloring were used in the diagram, making it orderly and elegant. There is a clearly drawn legend (Fig. 4.24).
In contrast to the seriousness and simplicity of other report covers, this cover is decorated with a variety of imagery, such as a phoenix and auspicious clouds. The appealing effect is one of goodwill and suggests the creative enthusiasm of hard-working geologists (Fig. 4.25).

This is China's first tectonic map on the scale of 1:3,000,000. The map had a profound impact at home and abroad and was widely recognized by geoscientists as an epoch-making and canonic achievement in the history of Asian tectonic studies (Fig. 4.31). 
Fig. 4.3 Geomorphological sketch of Shirenfeng tungsten mine, Shixing, Guangdong (sheet 2) [3]

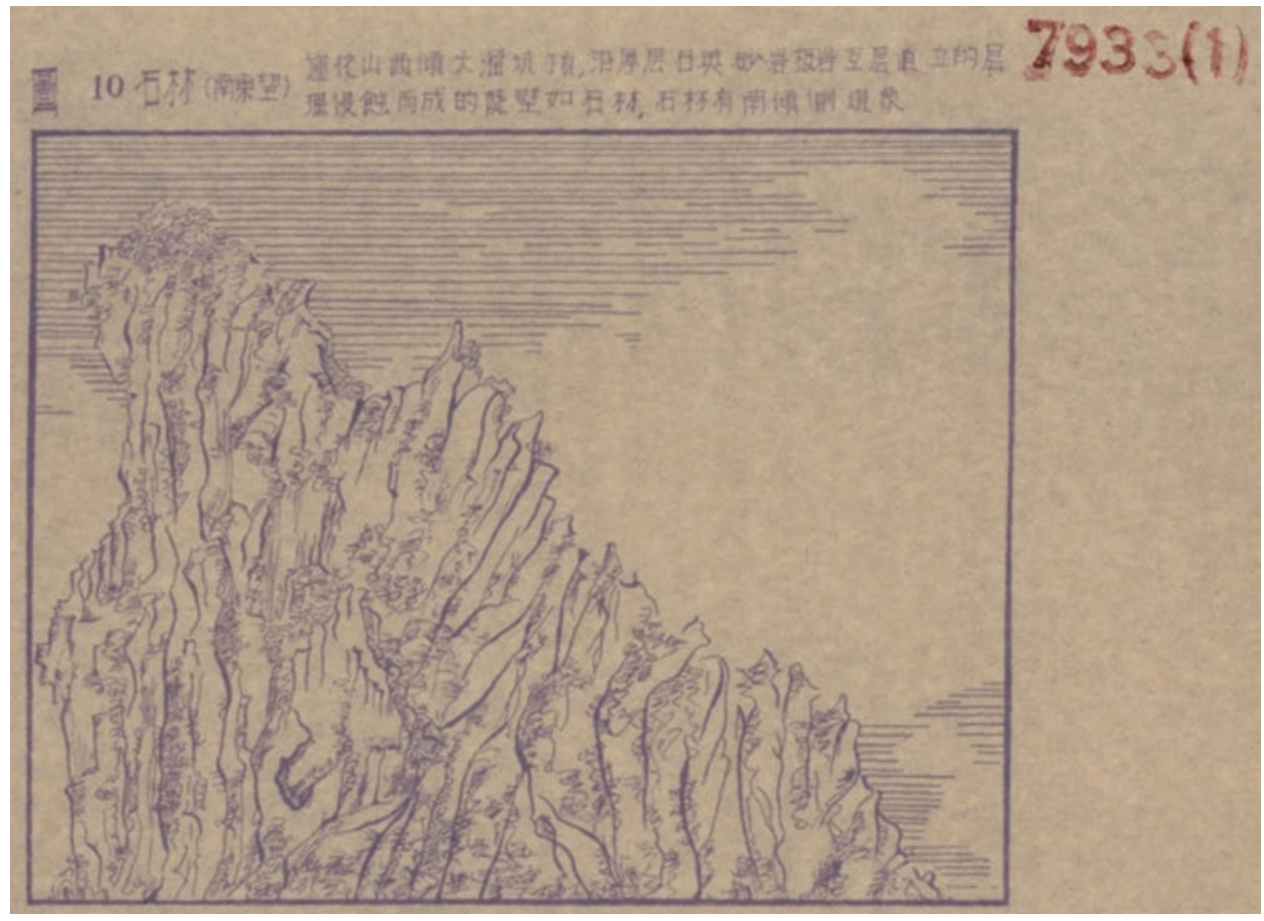

The monochromatic map is rich in content, with clear geological signs and depicting diverse terrain (Fig. 4.32).

The multi-color quaternary geological map is primarily rendered in yellow and green, with a double-line frame and a latitudinal and longitudinal grid. The colors are harmonious, while the content of the map is rich (Fig. 4.33).

This tectonic map with internal sheet division depicts complex content with bright and contrasting colors. It was published as a print from a fair drawing (Fig. 4.35).

The diagram appears three-dimensional, with distinct, vivid layers of color. It includes a complete and detailed legend and other features (Fig. 4.39).

The map was created with clear lines in elegant colors rendered using a traditional Chinese brush painting technique. The color transitions are natural and smooth (Fig. 4.40).
The columnar description is concise and easy to grasp (Fig. 4.41).

Contrasting colors were used to create an effect of color fluidity (Fig. 4.45).

The texture is dense, orderly, and clean, with a subtle tint of color in certain areas, making the overall drawing precise and refreshing (Fig. 4.49).

The sketch depicts richly complex structures, with distinct blocks and neatly labeled geological elements (Fig. 4.50).

The diagram employs the perspective method to describe ore bodies (Fig. 4.51).

The balanced and harmonious, brightly colored map is divided into four parts (Fig. 4.52).

The map was drawn in optimal density with elegant colors (Fig. 4.54). 
Fig. 4.4 Diagram of a seam columnar section of Yaojie coal mine [4]

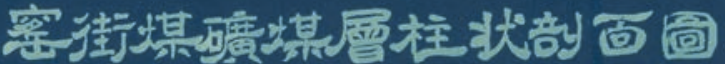

$$
1: 100
$$

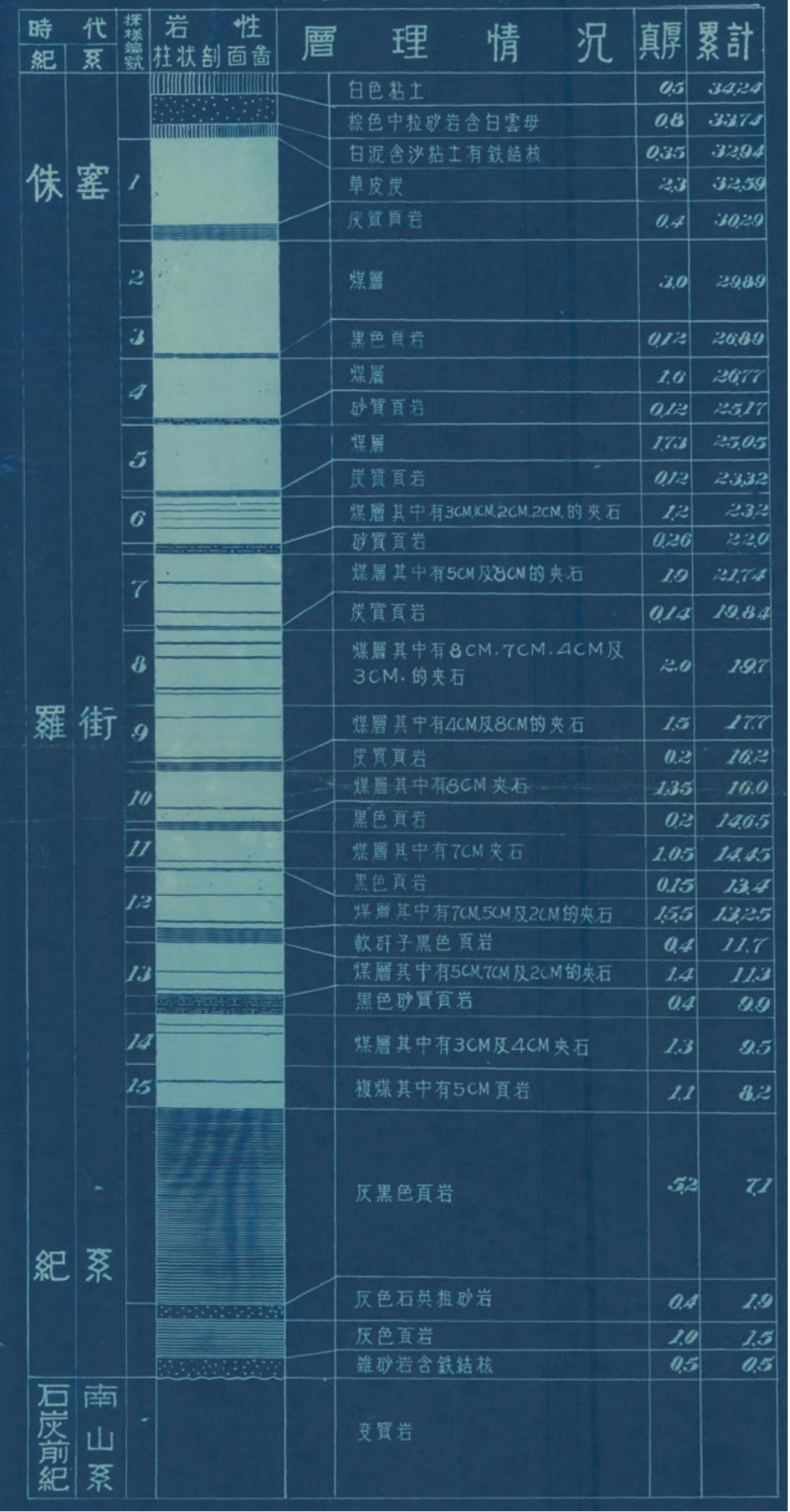




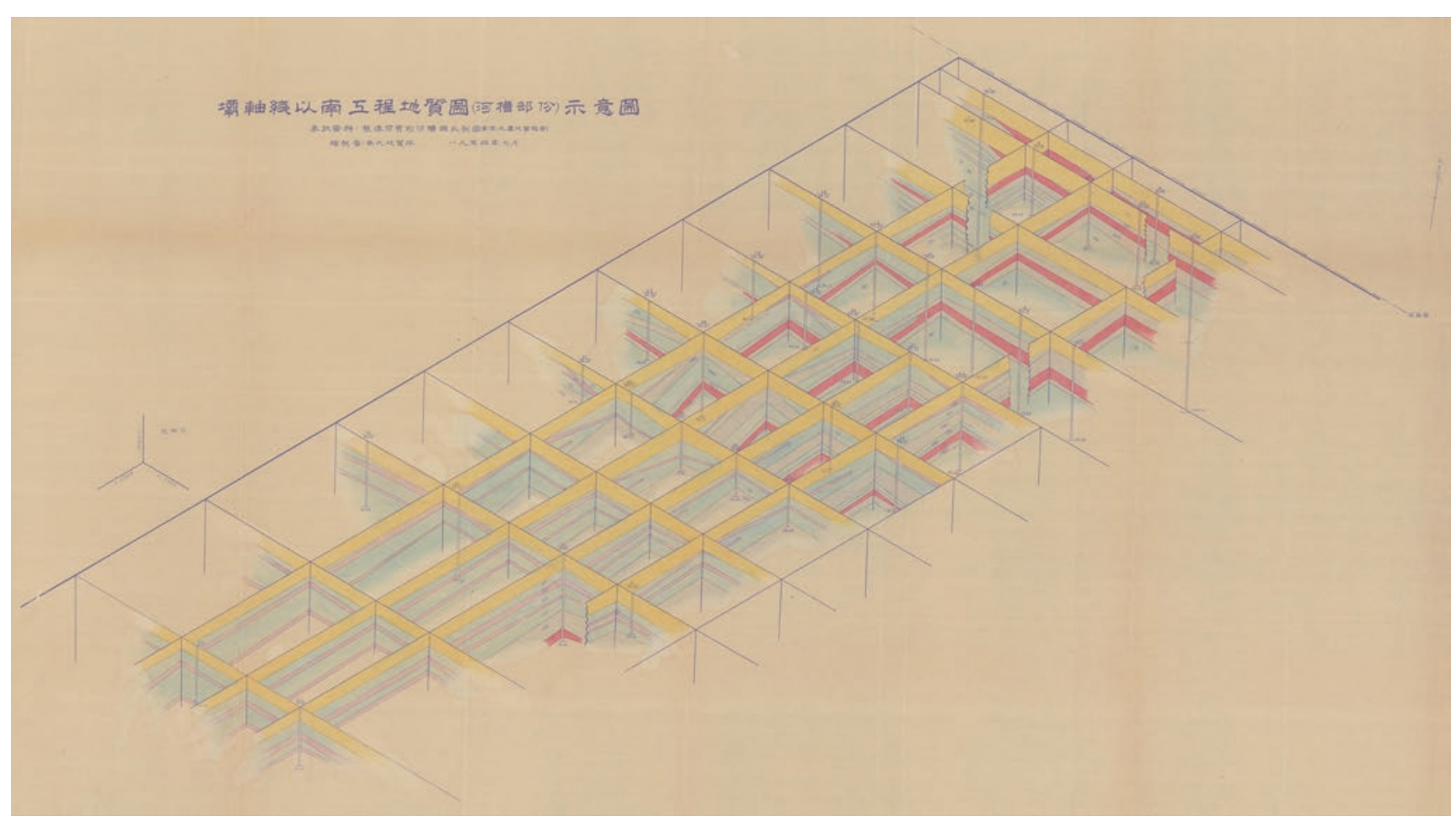

Fig. 4.5 Schematic diagram of the engineering geological map of areas south of the dam axis (river bed section) [5] 


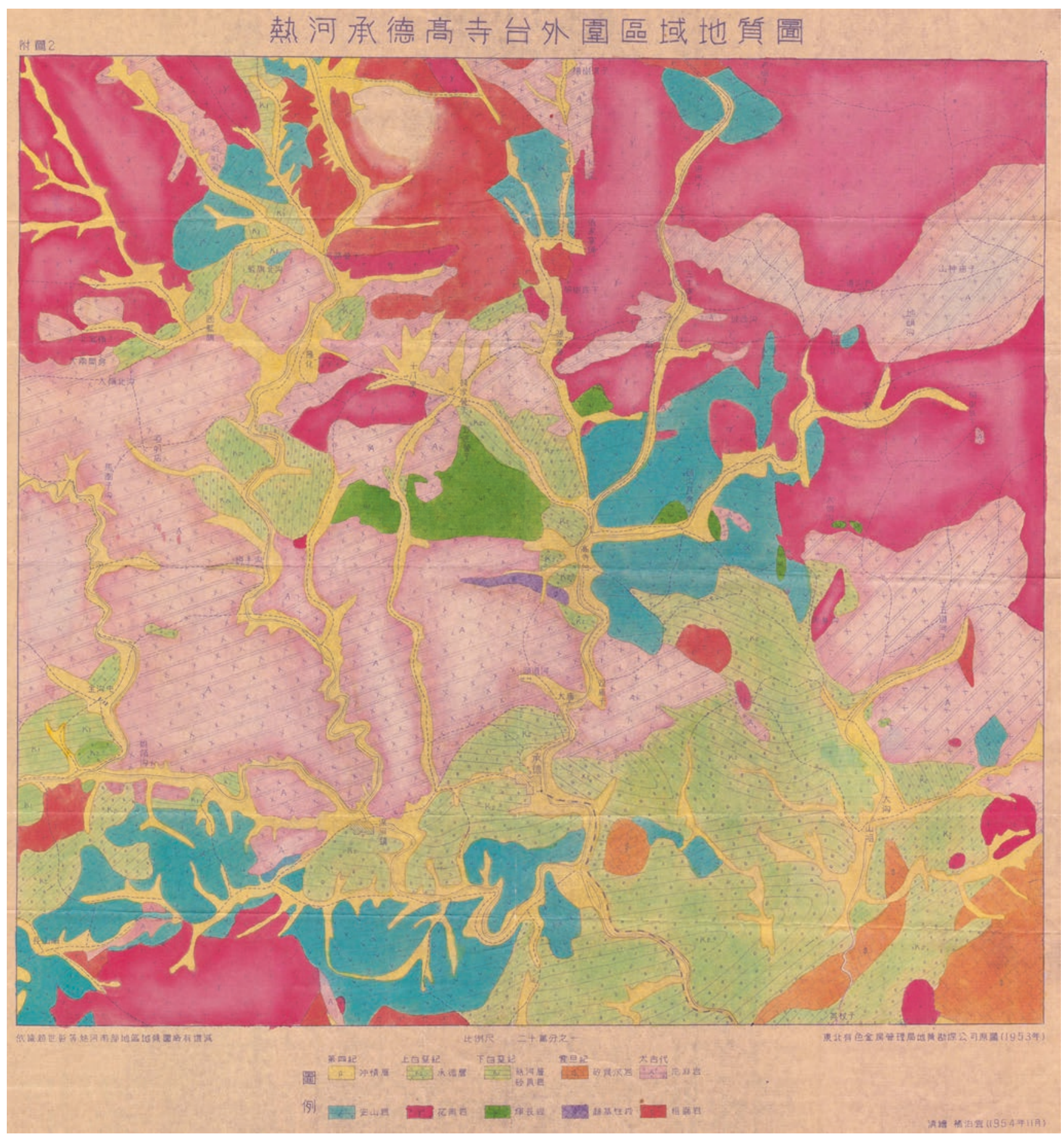

Fig. 4.6 Geological map of areas peripheral to Gaositai, Chengde, Rehe [6] 


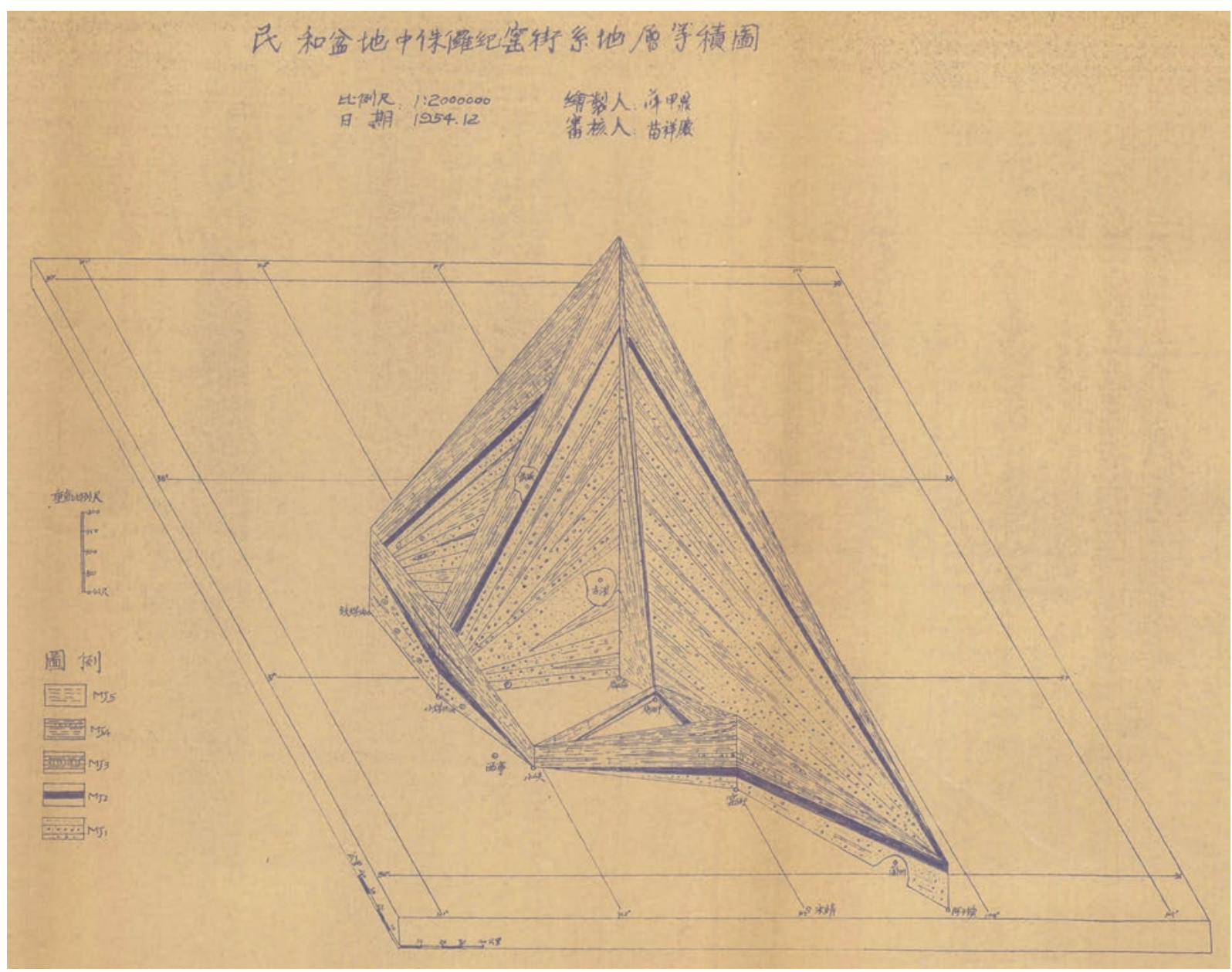

Fig. 4.7 Equal area chart of the middle Jurassic stratum of Yaojie coal mine in the Minhe Basin [7] 


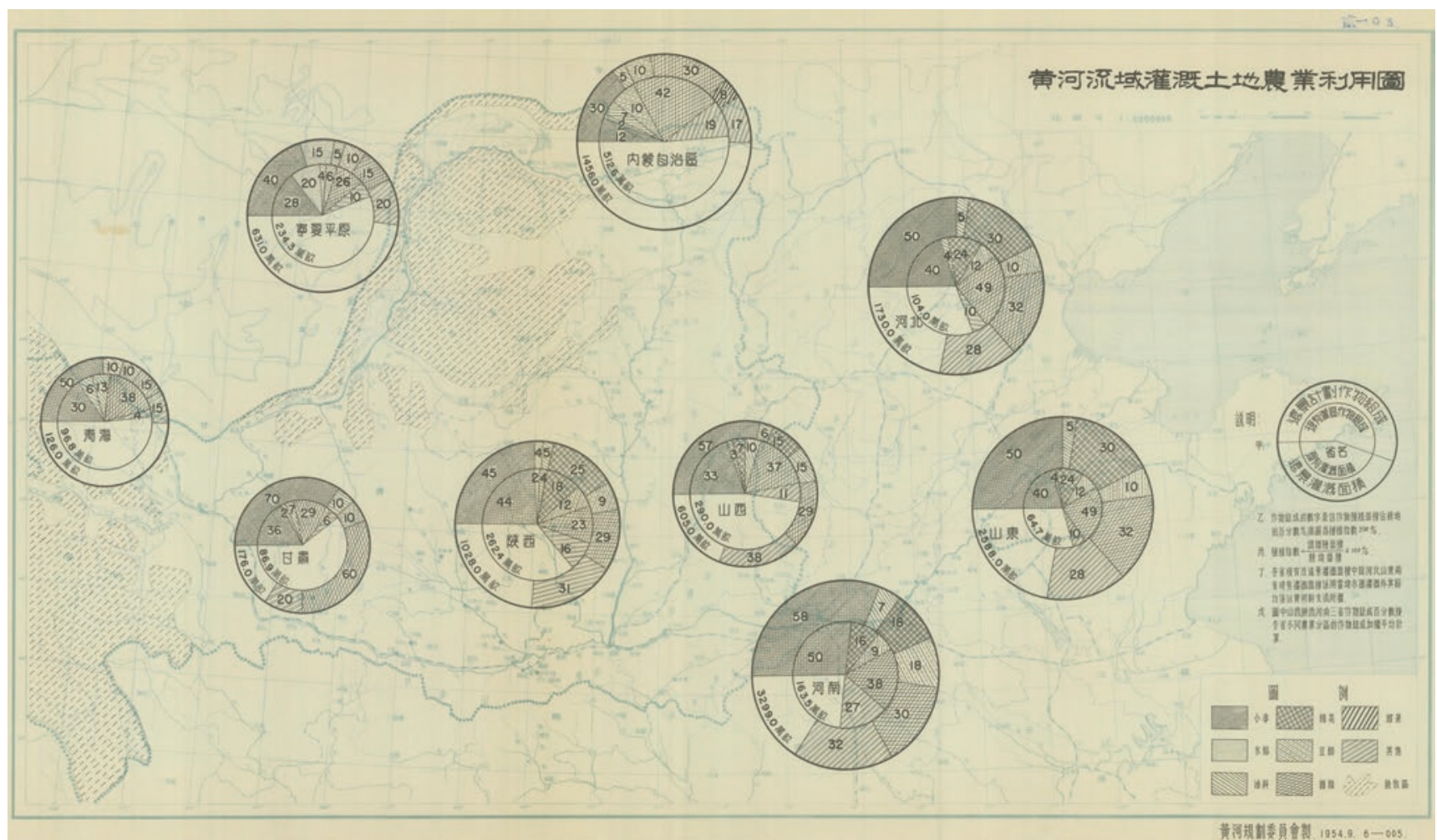

Fig. 4.8 Agricultural utilization map of irrigated land in the Yellow River Basin [8] 


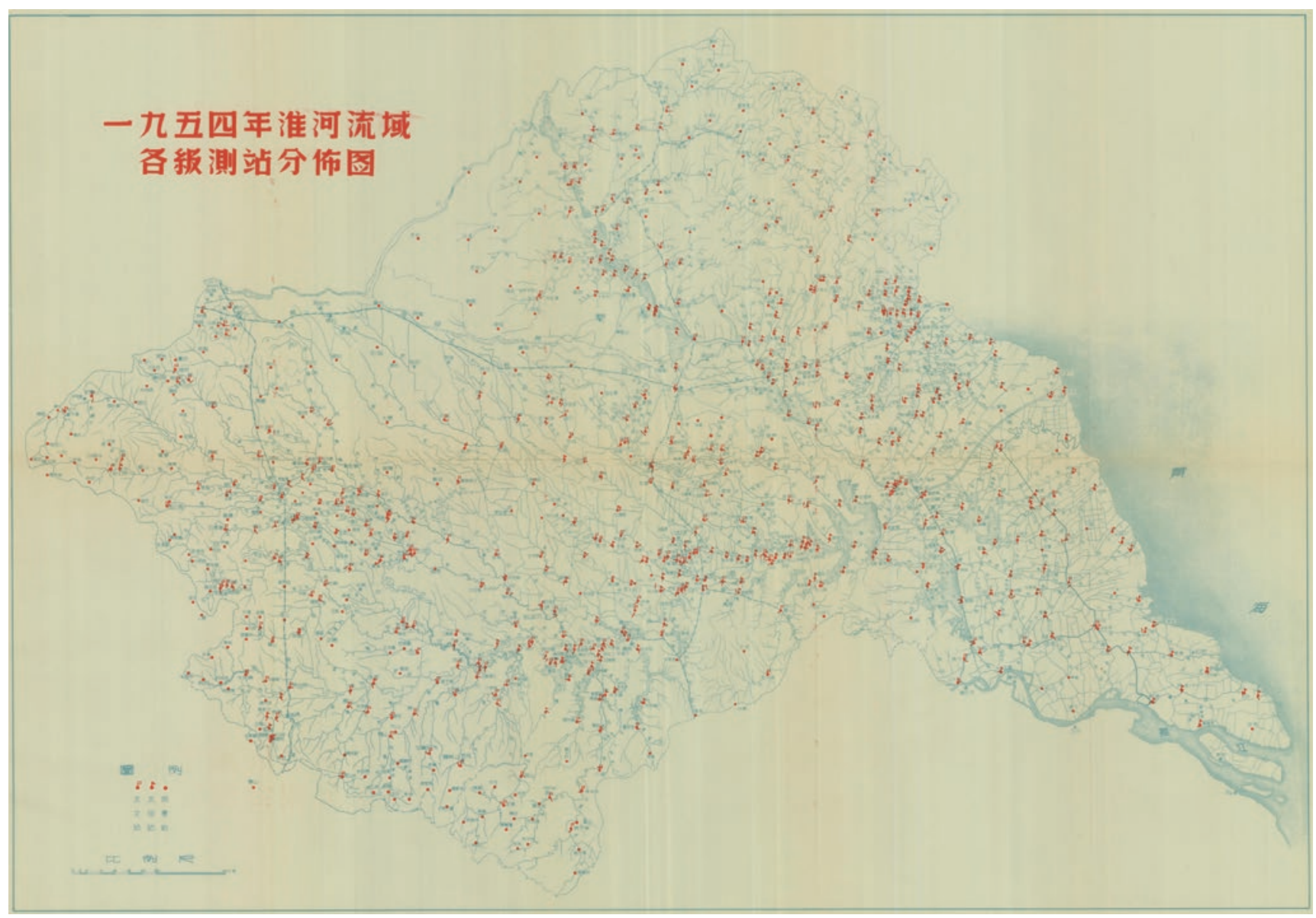

Fig. 4.9 Distribution of observation stations at various levels in the Huaihe River Basin in 1954 [9] 
Fig. 4.10 Topographic

sketch of the Ningjiahe River Dam, Shawan County [10]

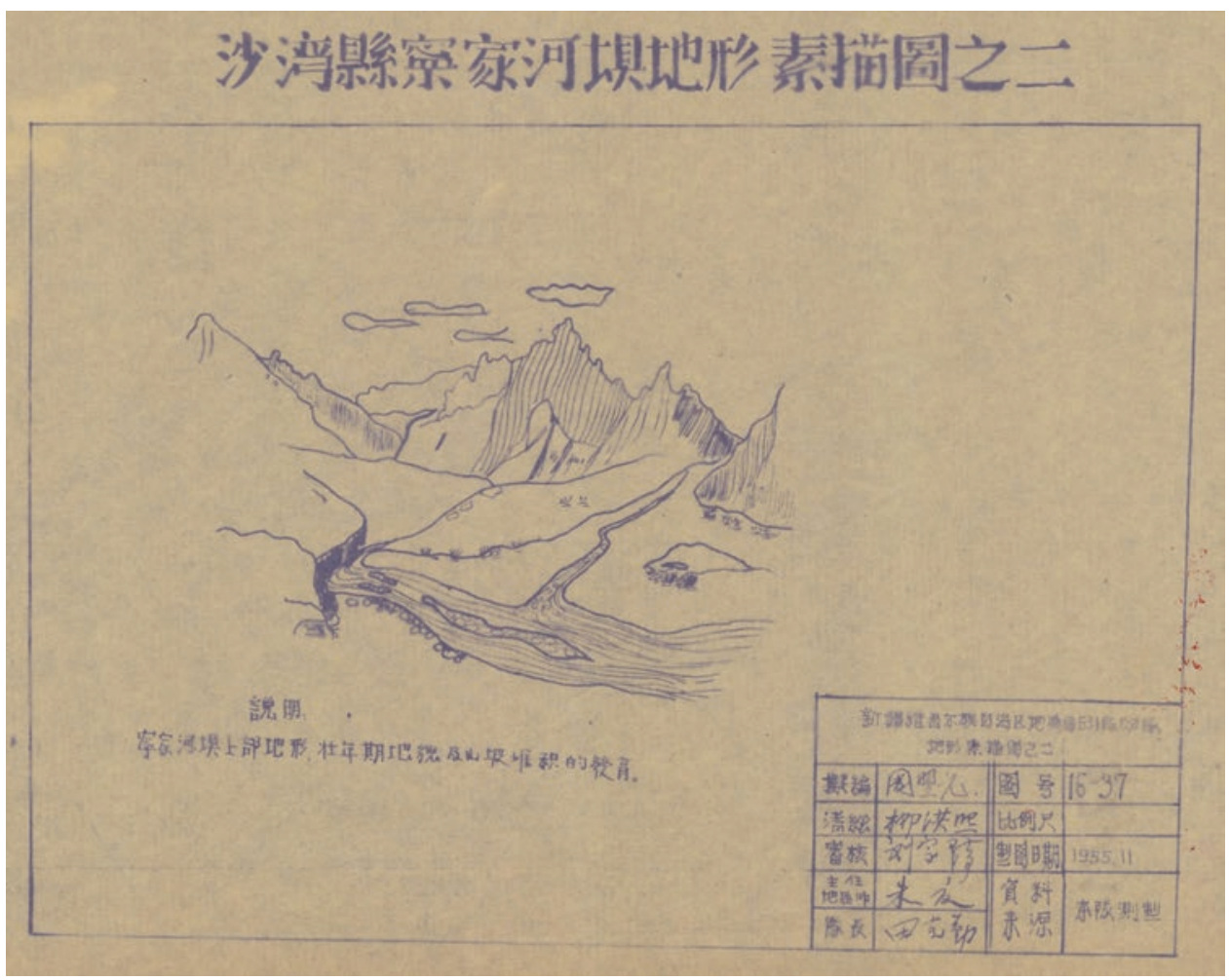

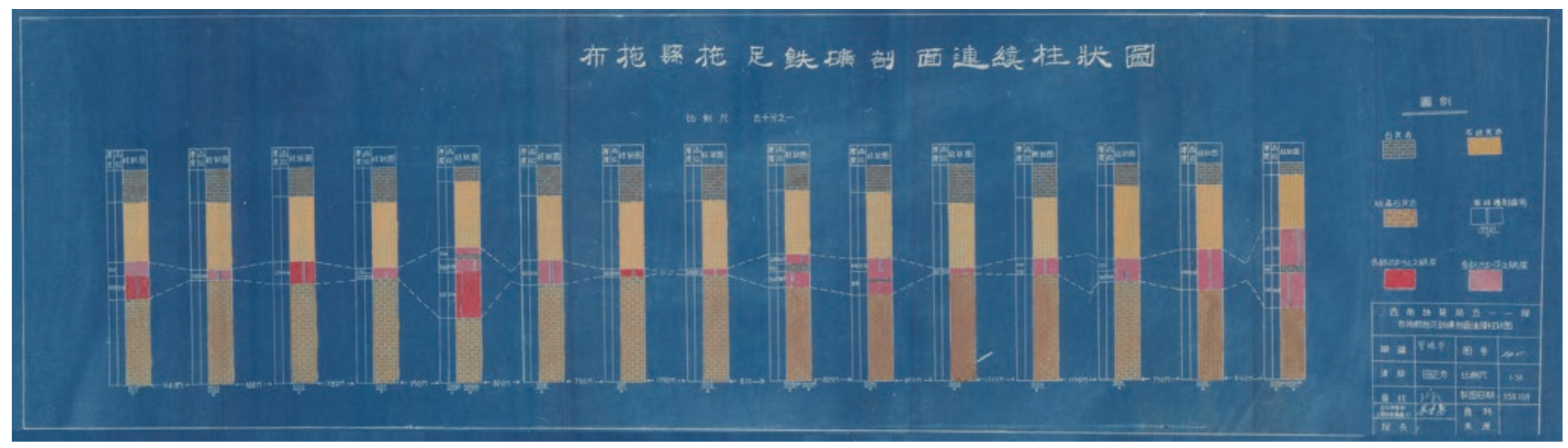

Fig. 4.11 Diagram of a continuous columnar section of Tuozu iron ore mine in Butuo County [11] 


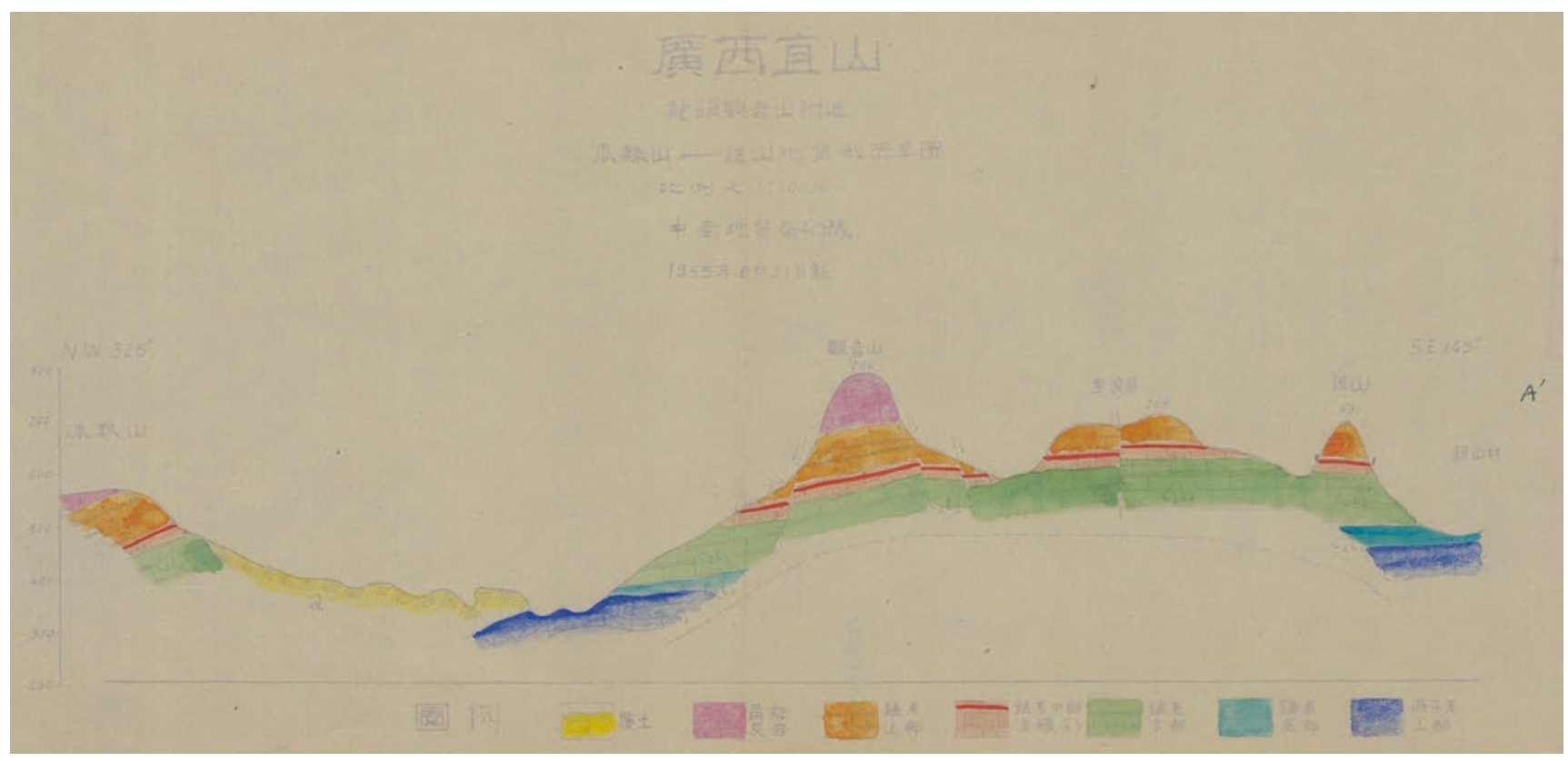

Fig. 4.12 Geological profile sketch of Mt. Guaran-Mt. Yinshan [12]

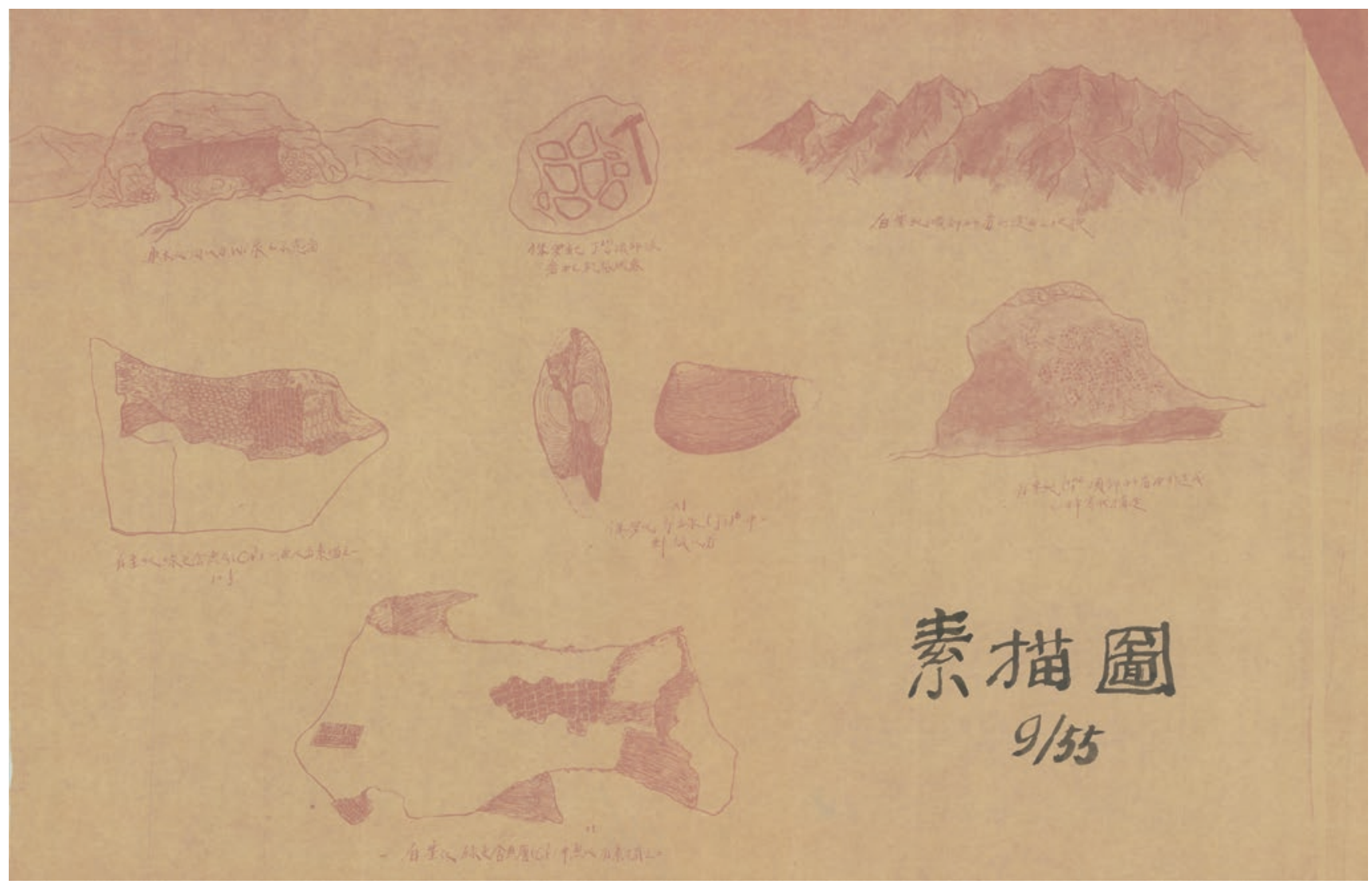

Fig. 4.13 Sketch attached to final geological report on Subashi in central Mt. Huoyan, the Turpan Basin [13] 


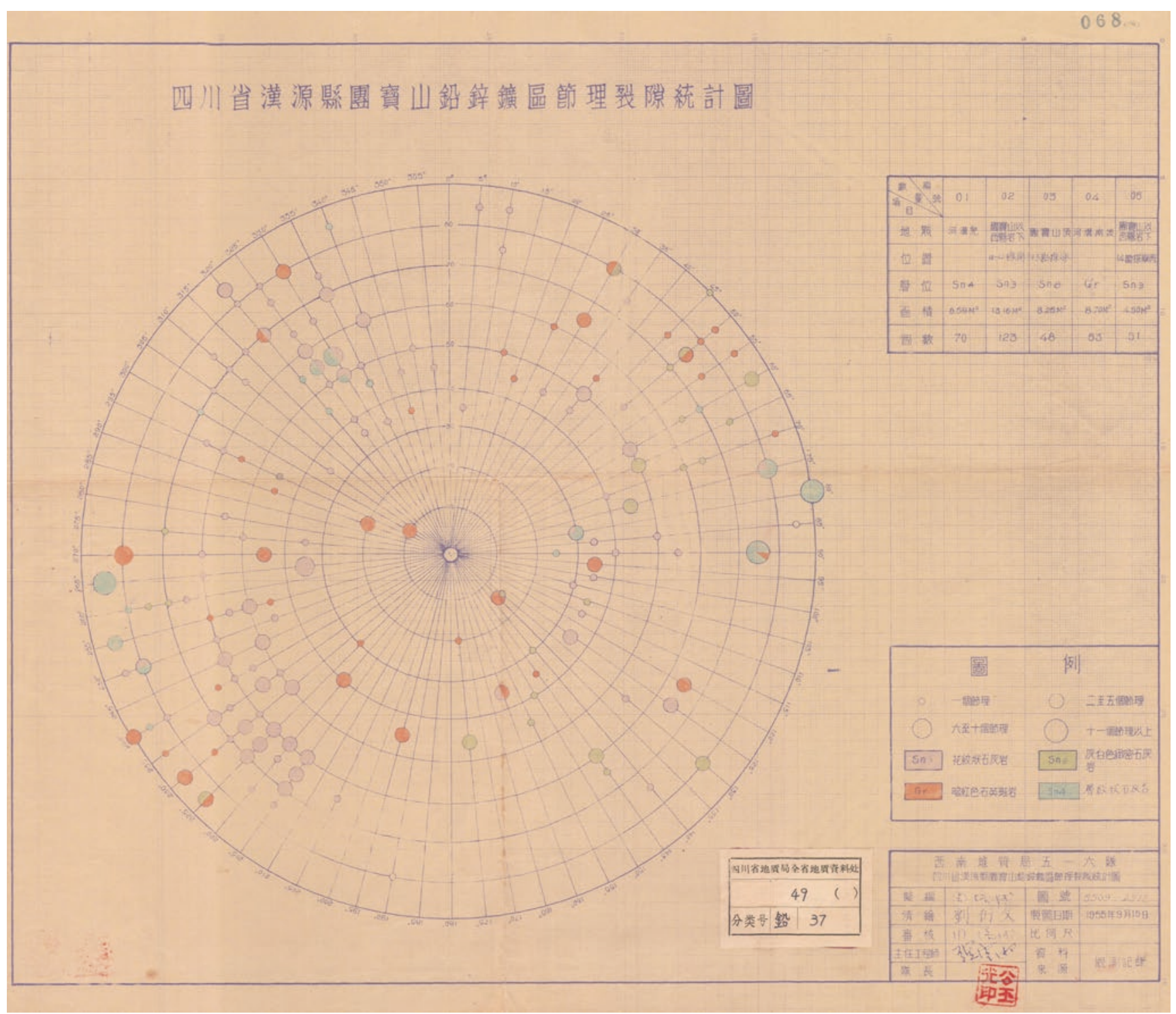

Fig. 4.14 Statistical diagrams of joints and fissures of the Tuanbaoshan lead-zinc mining area in Hanyuan County, Sichuan Province [14] 


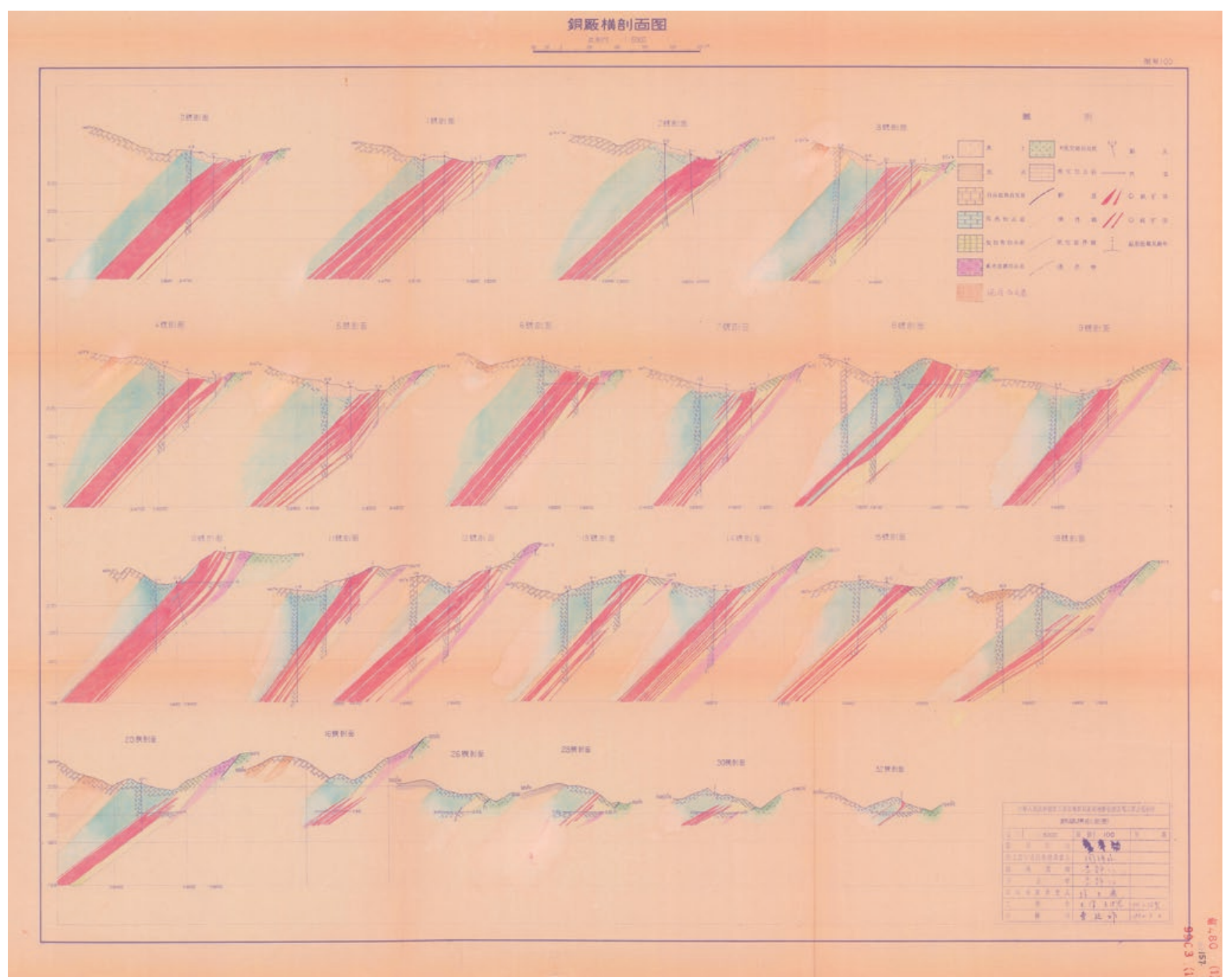

Fig. 4.15 Sectional diagram of a copper mine in the adjoining area of Yimen, Shuangbai, and Eshan counties, Yunnan Province [15] 
Fig. 4.16 Topographic and geological profile of Tuozu iron ore mine in Butuo

County [16]

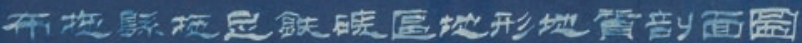

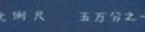

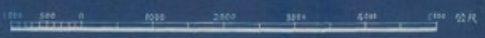

\section{E}

(c)

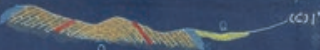

(c)

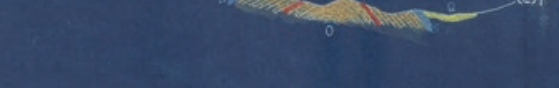

(B)j

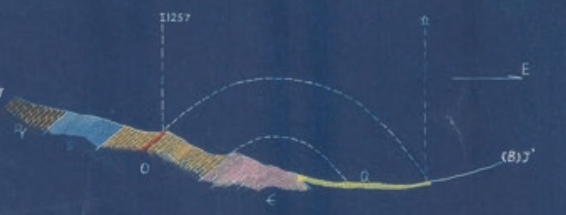

aik

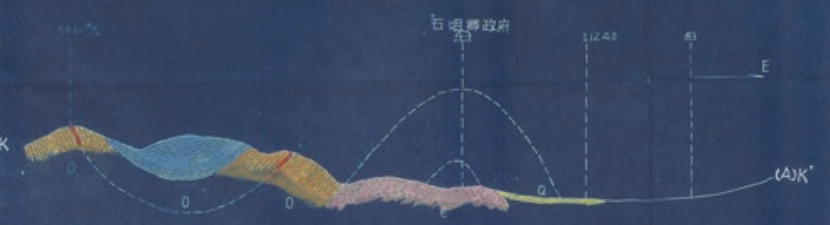

\section{圆 例}

$\square$ 第四跑

Fis $x$ 武祀

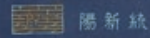

志留犯

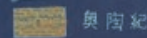

口] 解绕层

I1240 地考点

$55210 \%$ 取样点

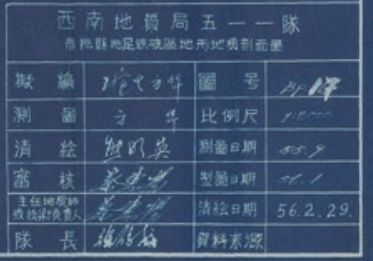




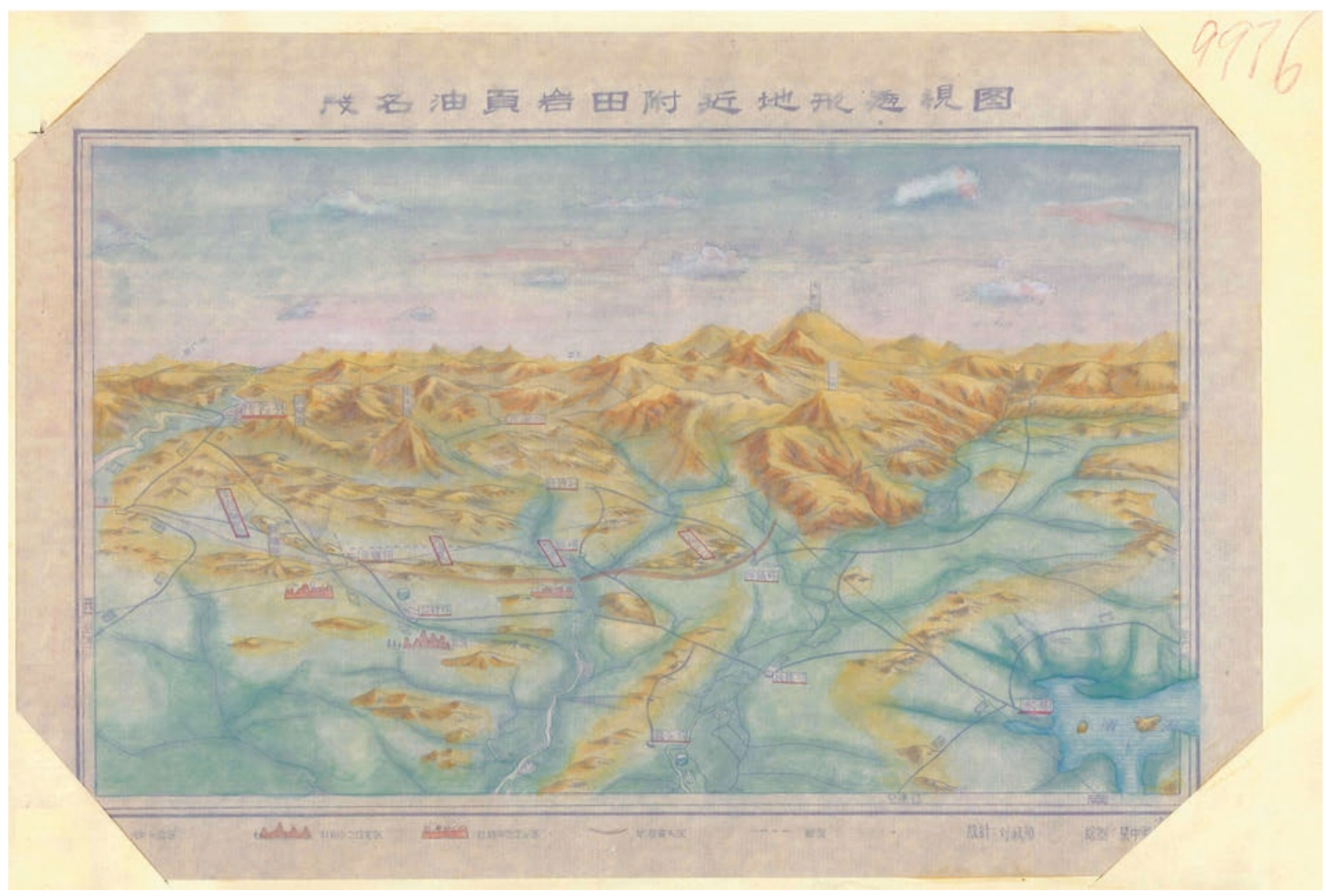

Fig. 4.17 Perspective view of the terrain in the vicinity of Maoming oil shale field [17] 
Fig. 4.18 Microscopic

illustration attached to

calculation table of a talc

reserve in Fanjiapuzi [18]

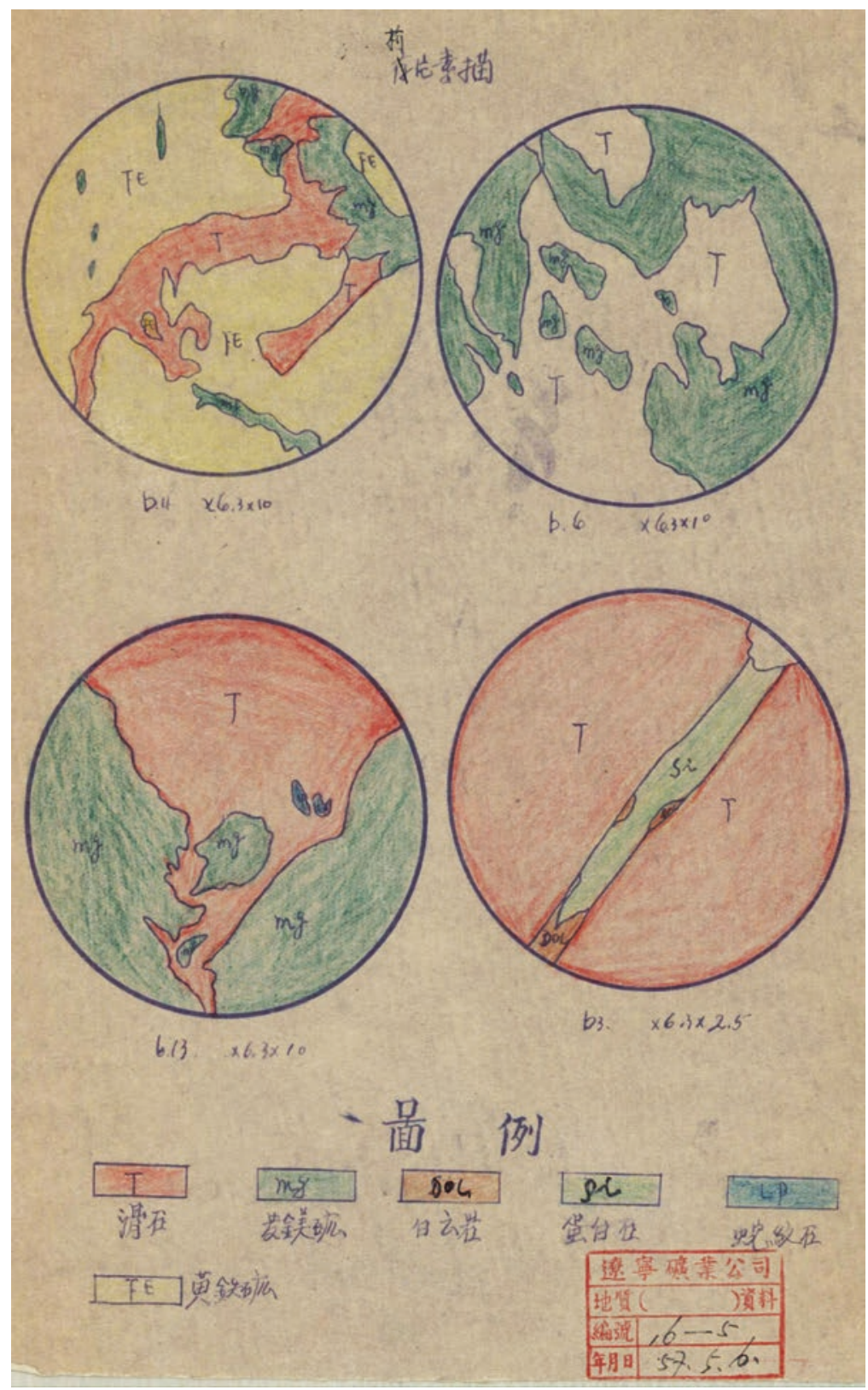




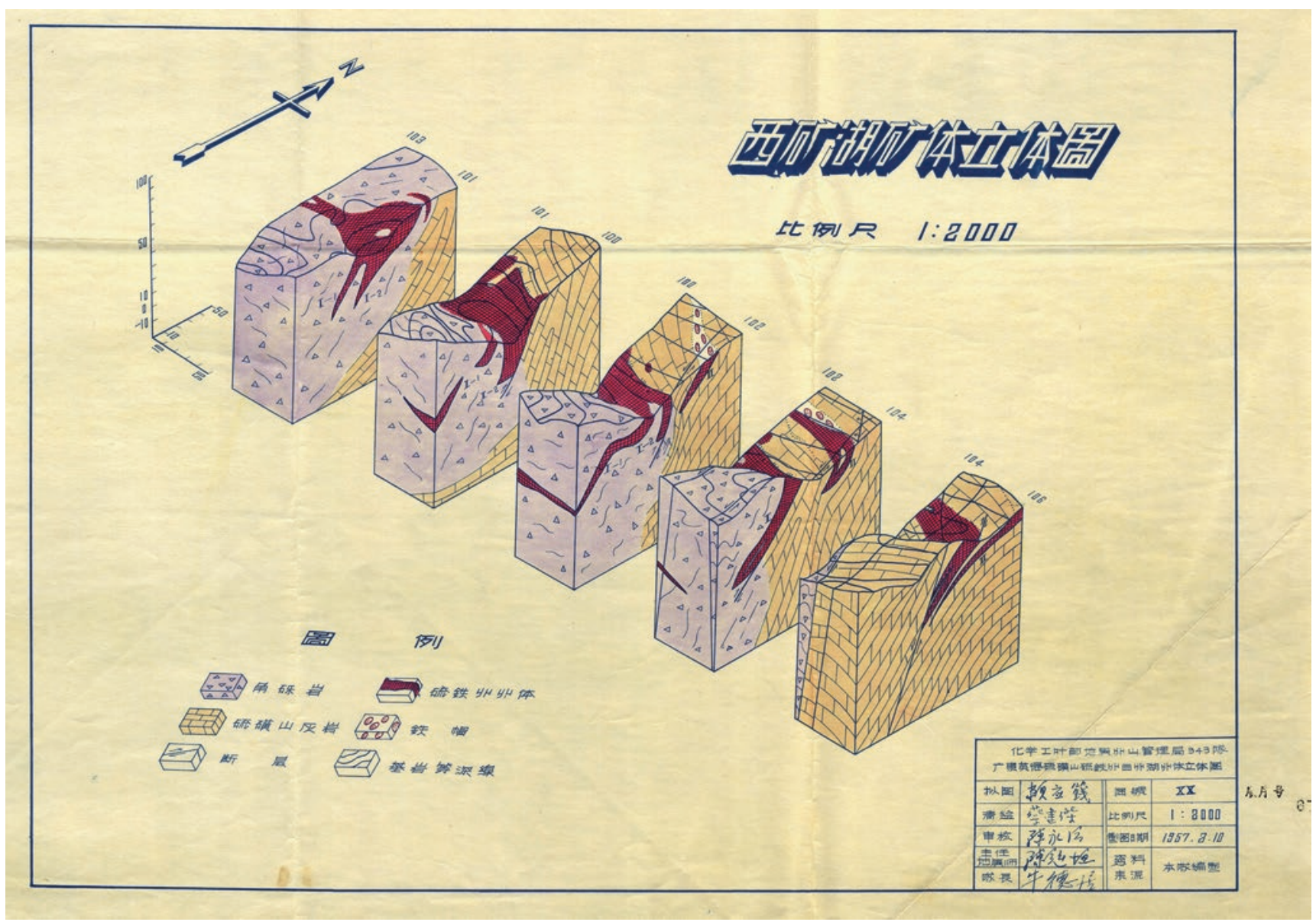

Fig. 4.19 Perspective diagram of ore bodies near West Lake [19] 


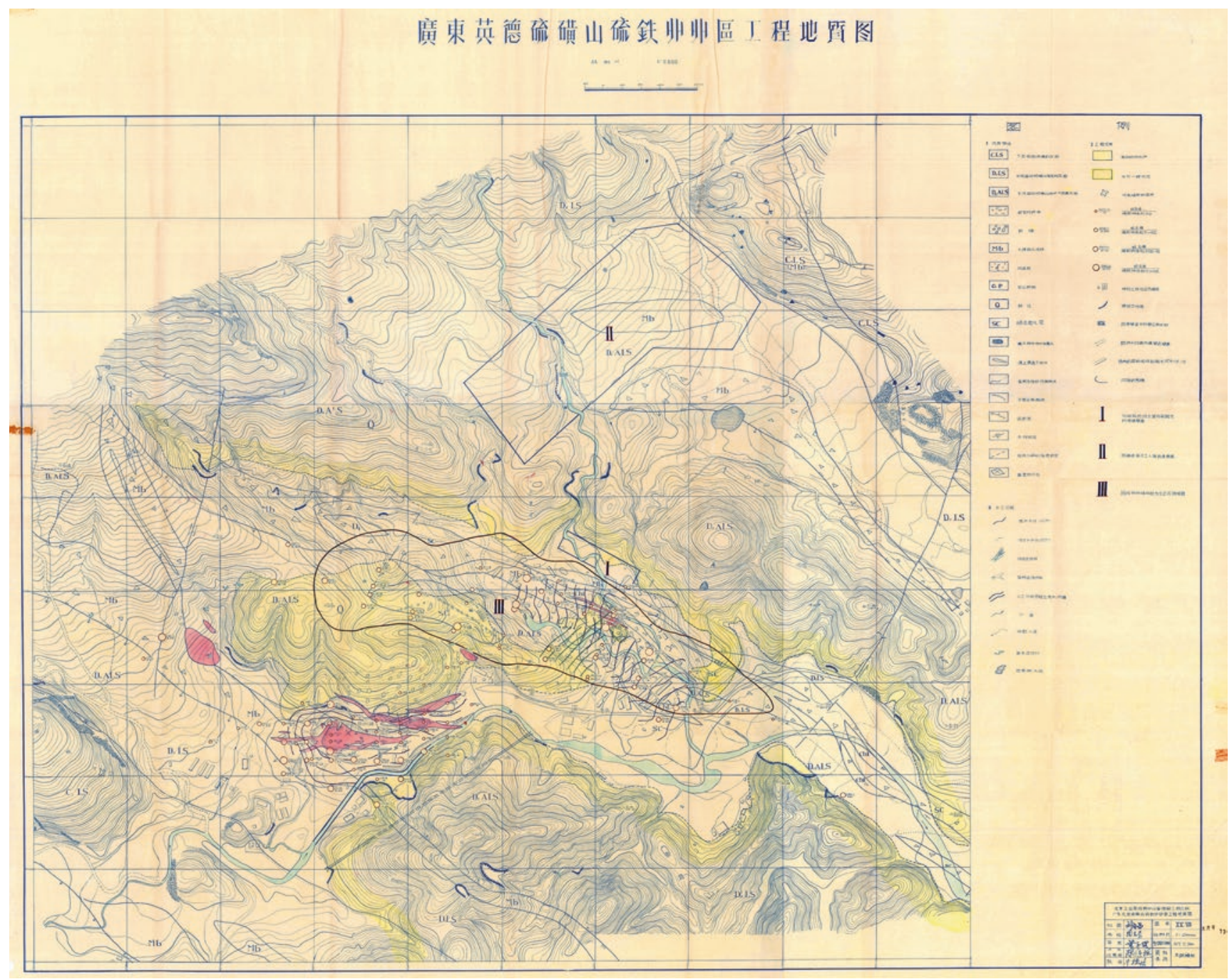

Fig. 4.20 Engineering geological map of pyrite mine in Mt. Liuhuang, Yingde, Guangdong Province [20] 


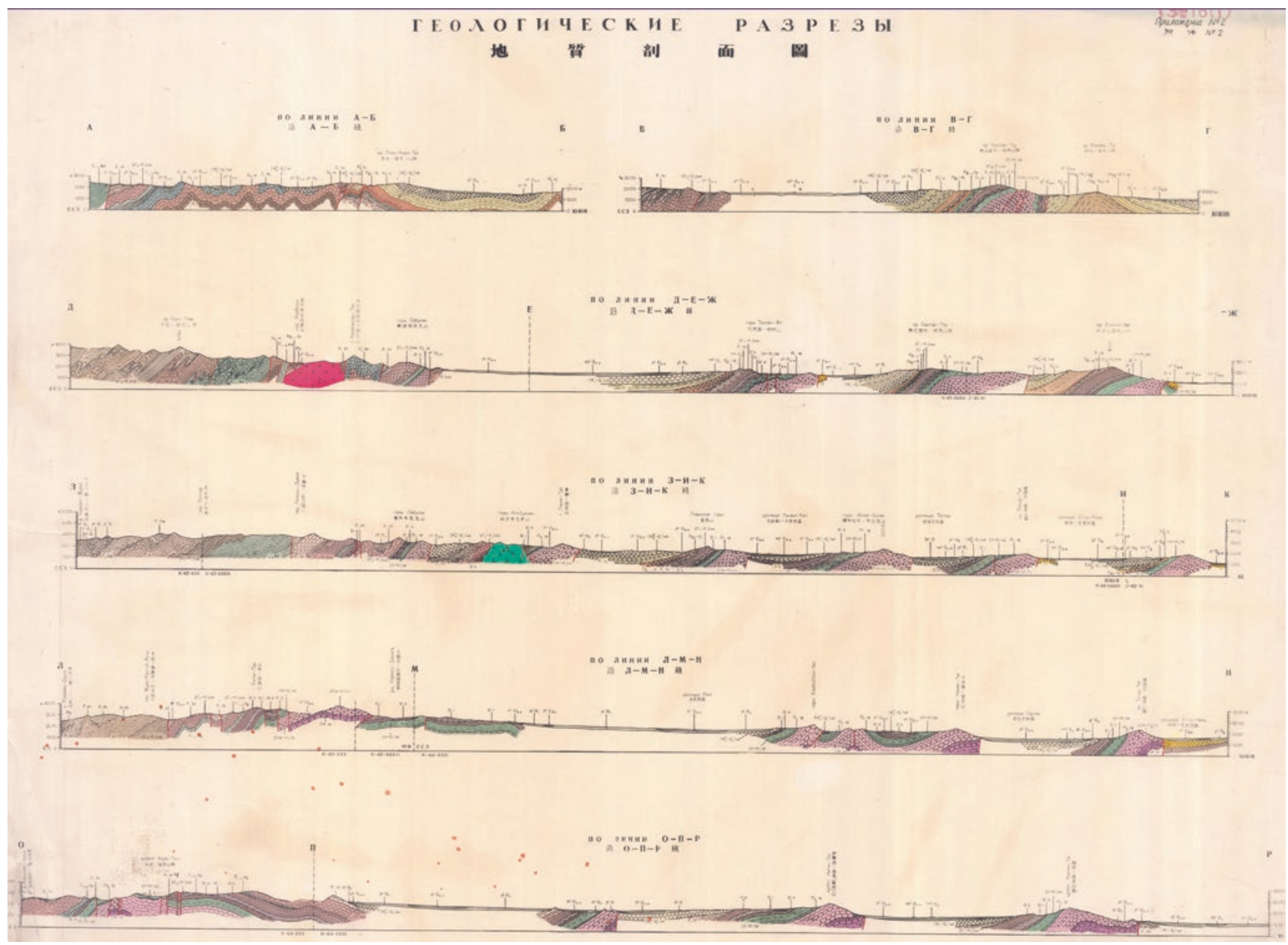

Fig. 4.21 Series of geological maps of the Kashi-Akesu region of Southern Mt. Tianshan, Xinjiang (1) [21]. (Source: Part of the series to geological map of the Kashi-Akesu region of Southern Mt. Tianshan, Xinjiang.) 
Fig. 4.22 Series of geological maps of the Kashi-Akesu region of Southern Mt. Tianshan, Xinjiang (2) [22]. (Source: Part of the series to geological map of the Kashi-Akesu region of Southern Mt.

Tianshan, Xinjiang.)

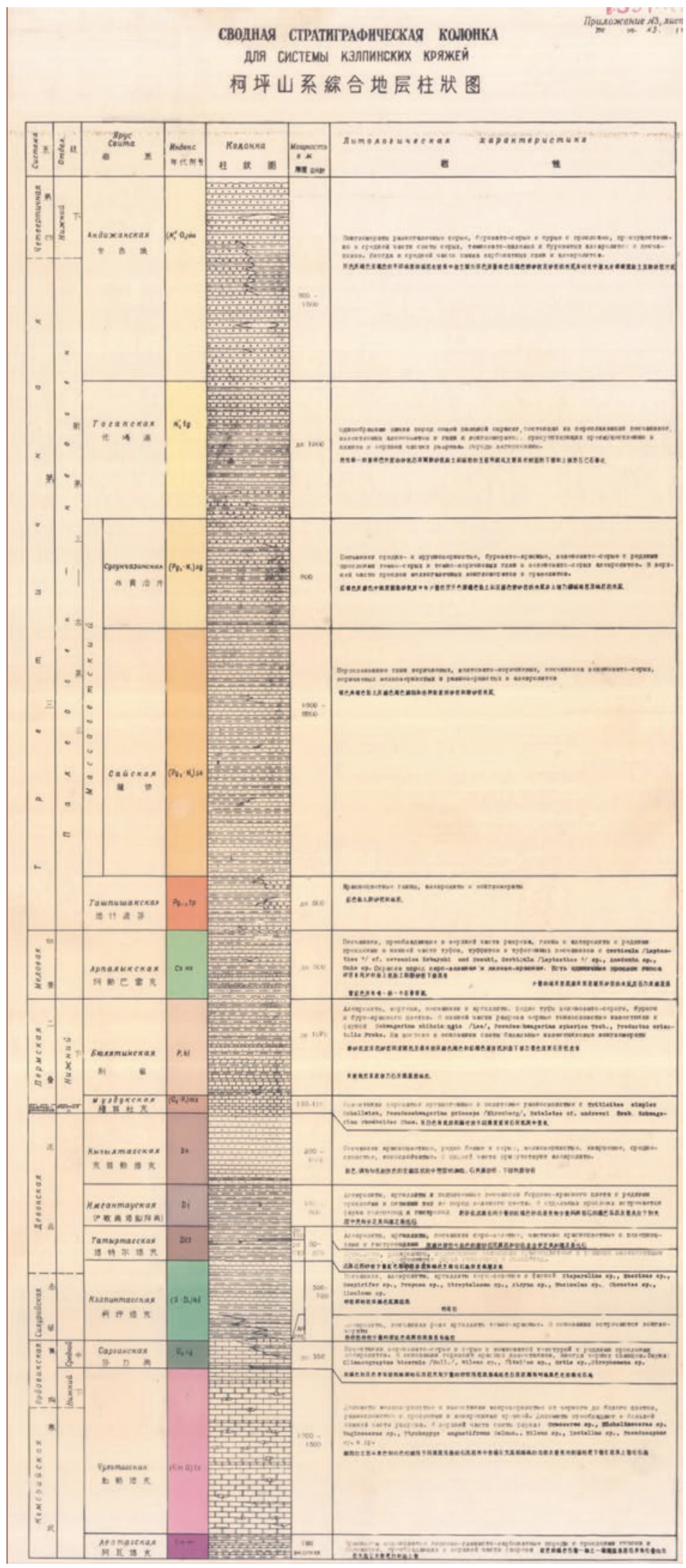


Fig. 4.23 Schematic drilling diagram [23]

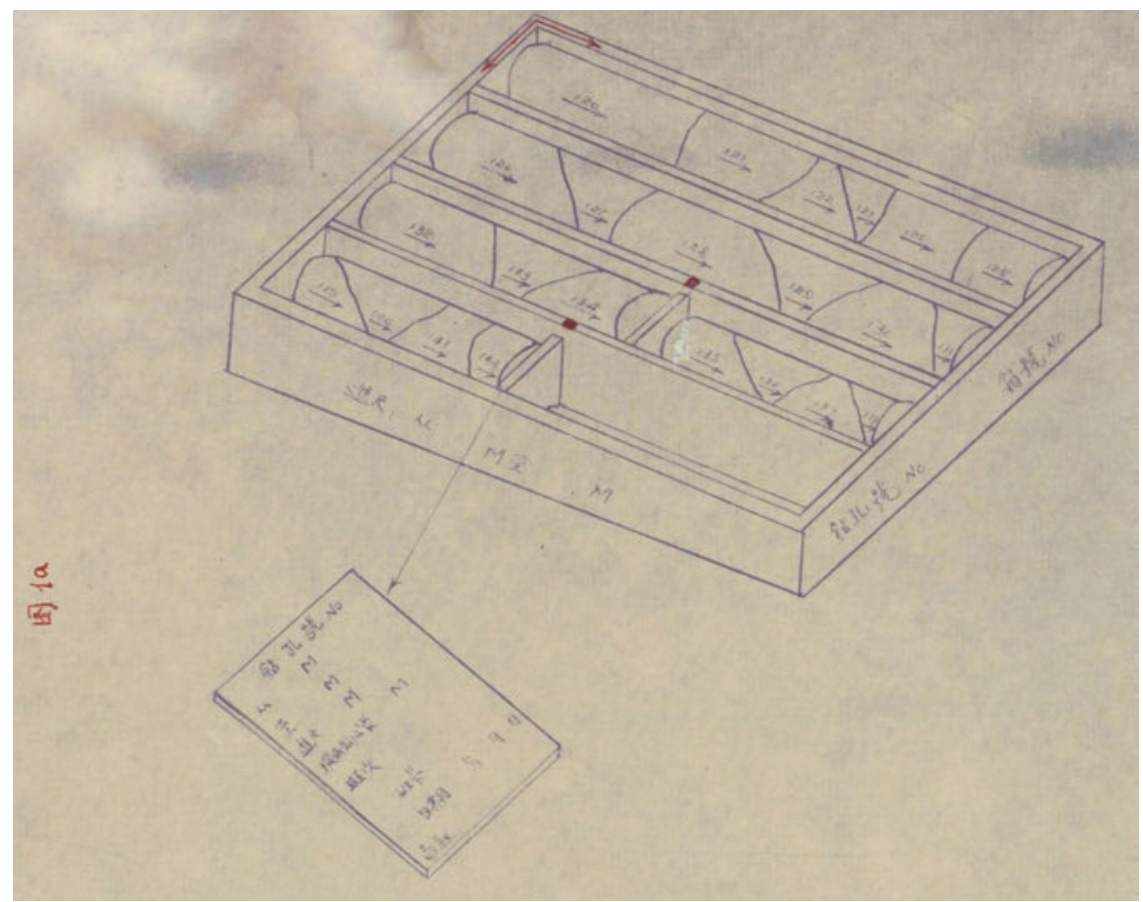




\section{賀兰山苏峪口至于沟南寺一带矿区区域水文地稹图}

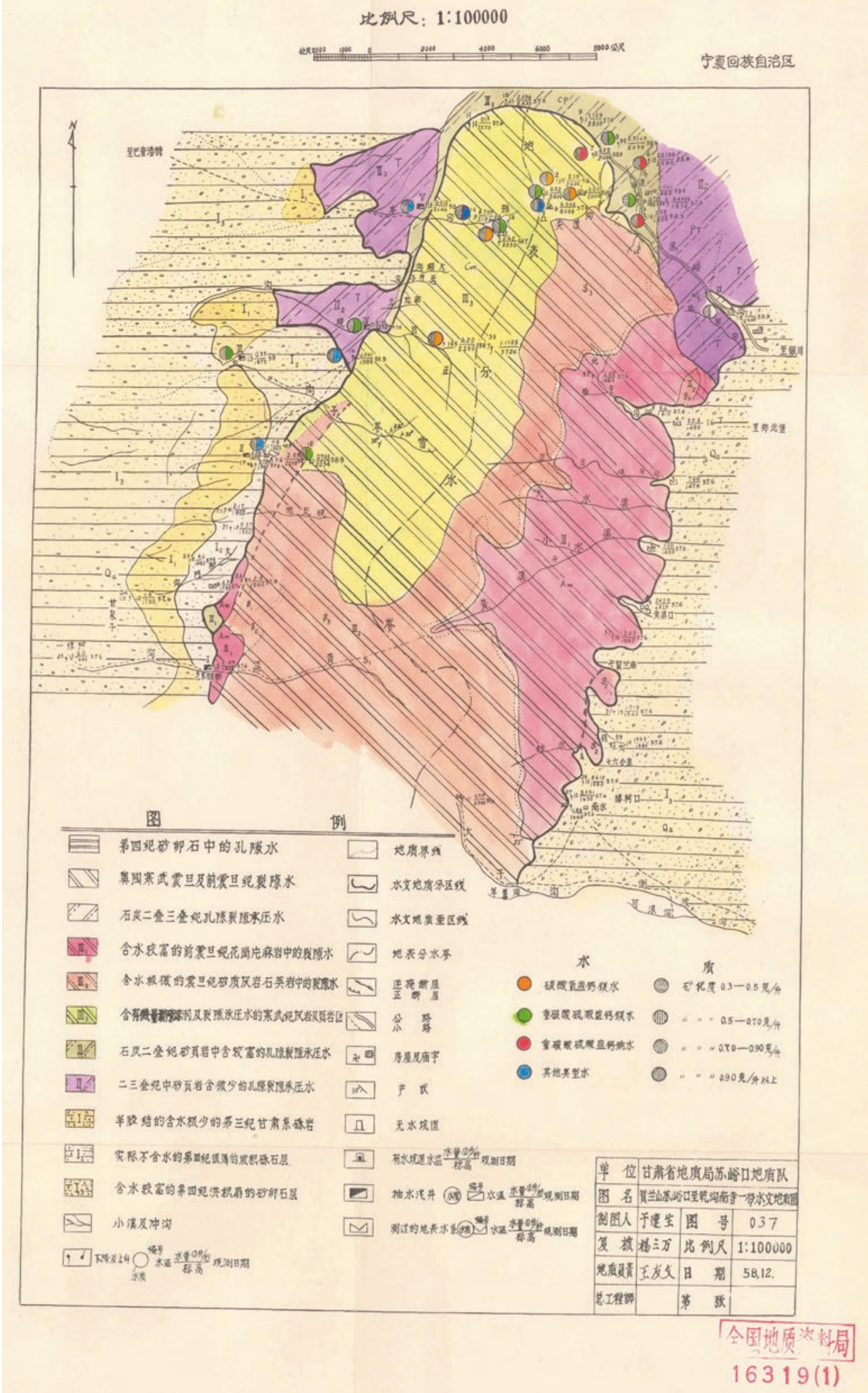

Fig. 4.24 Regional hydrological and geological map of the mining areas in the Suyukou, Yugou, and Nansi vicinities of Mt. Helan mountain [24] 


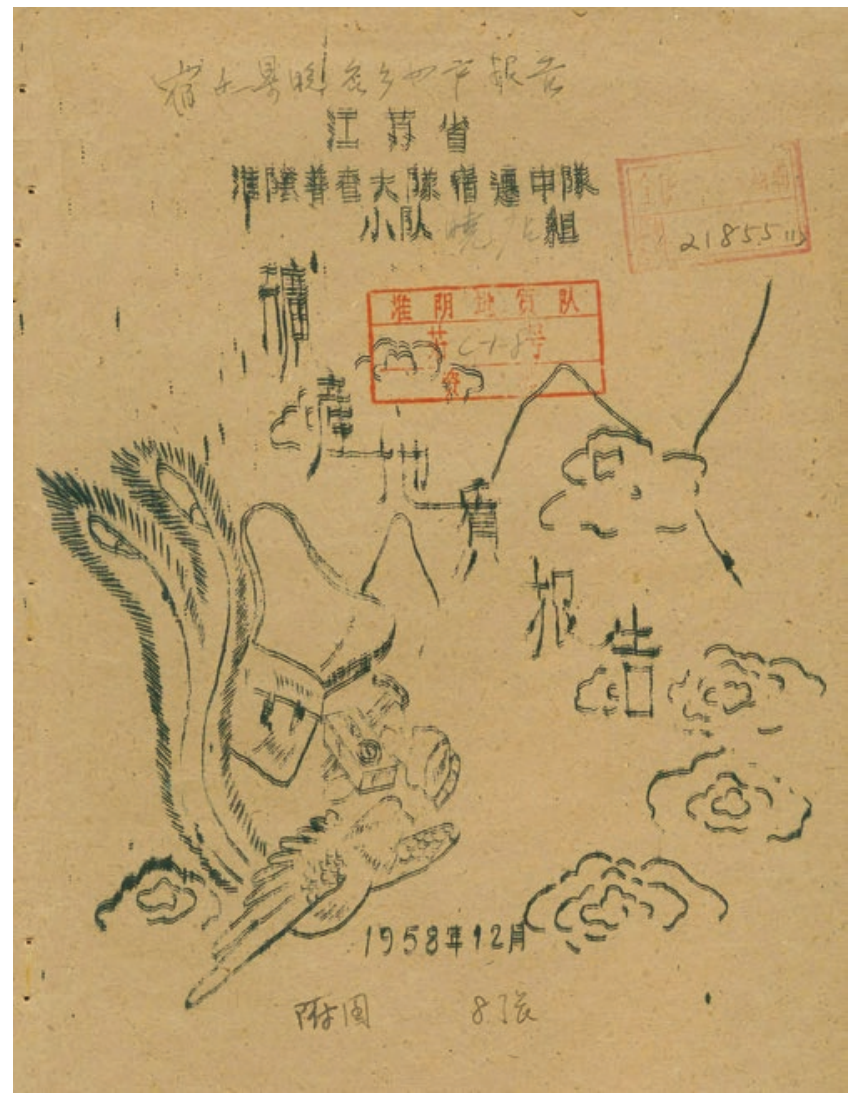

Fig. 4.25 Mineral geology report (cover) [25]

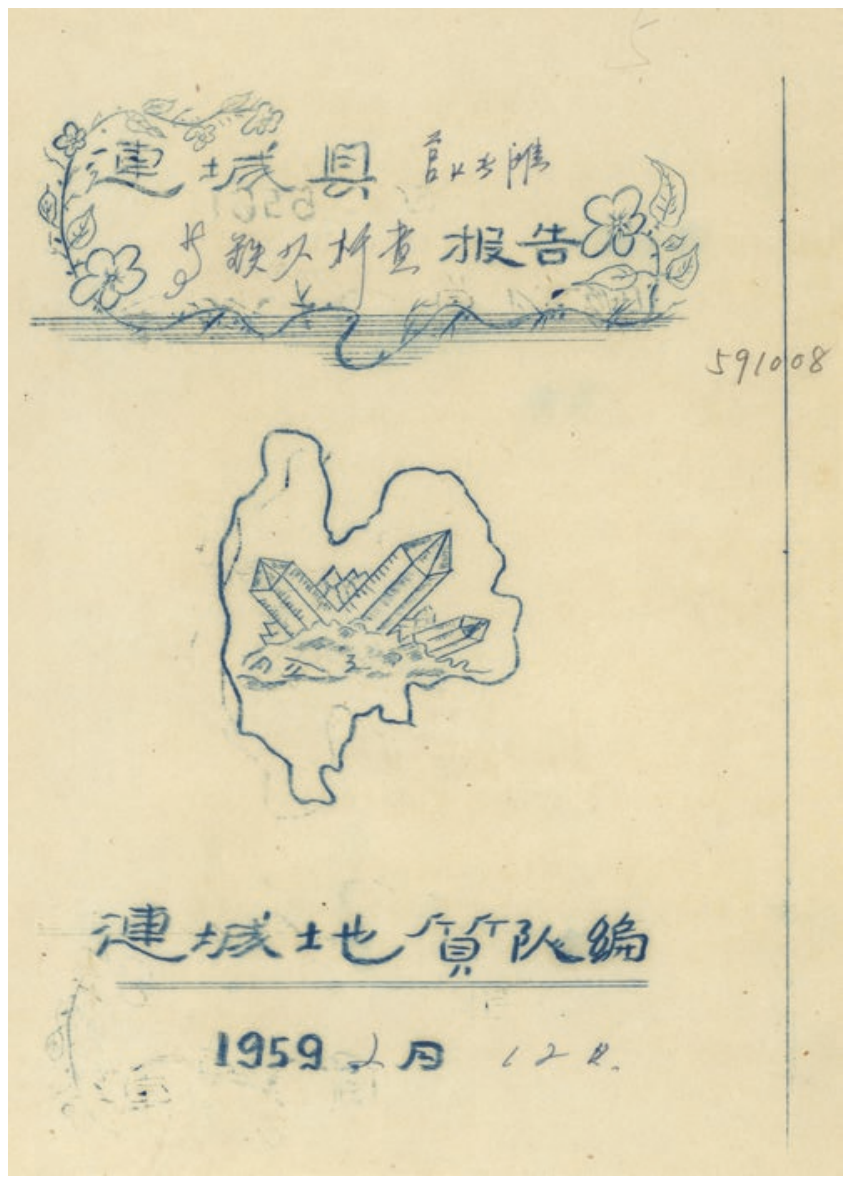

Fig. 4.26 Cover of the report on mineral exploration in Liancheng County [26] 


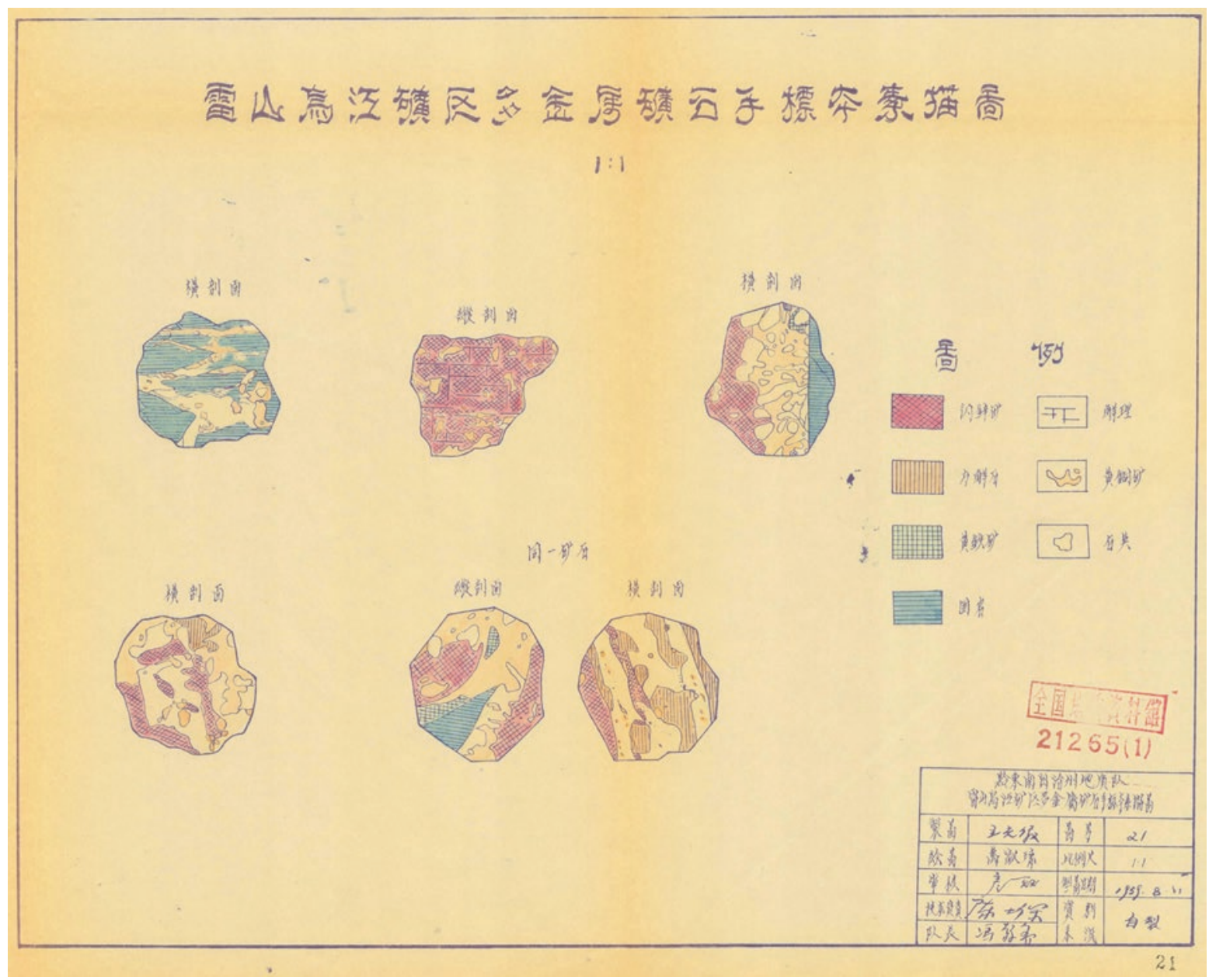

Fig. 4.27 Sketches of various polymetallic ore specimens from the Wujiang mining area of Leishan [27] 


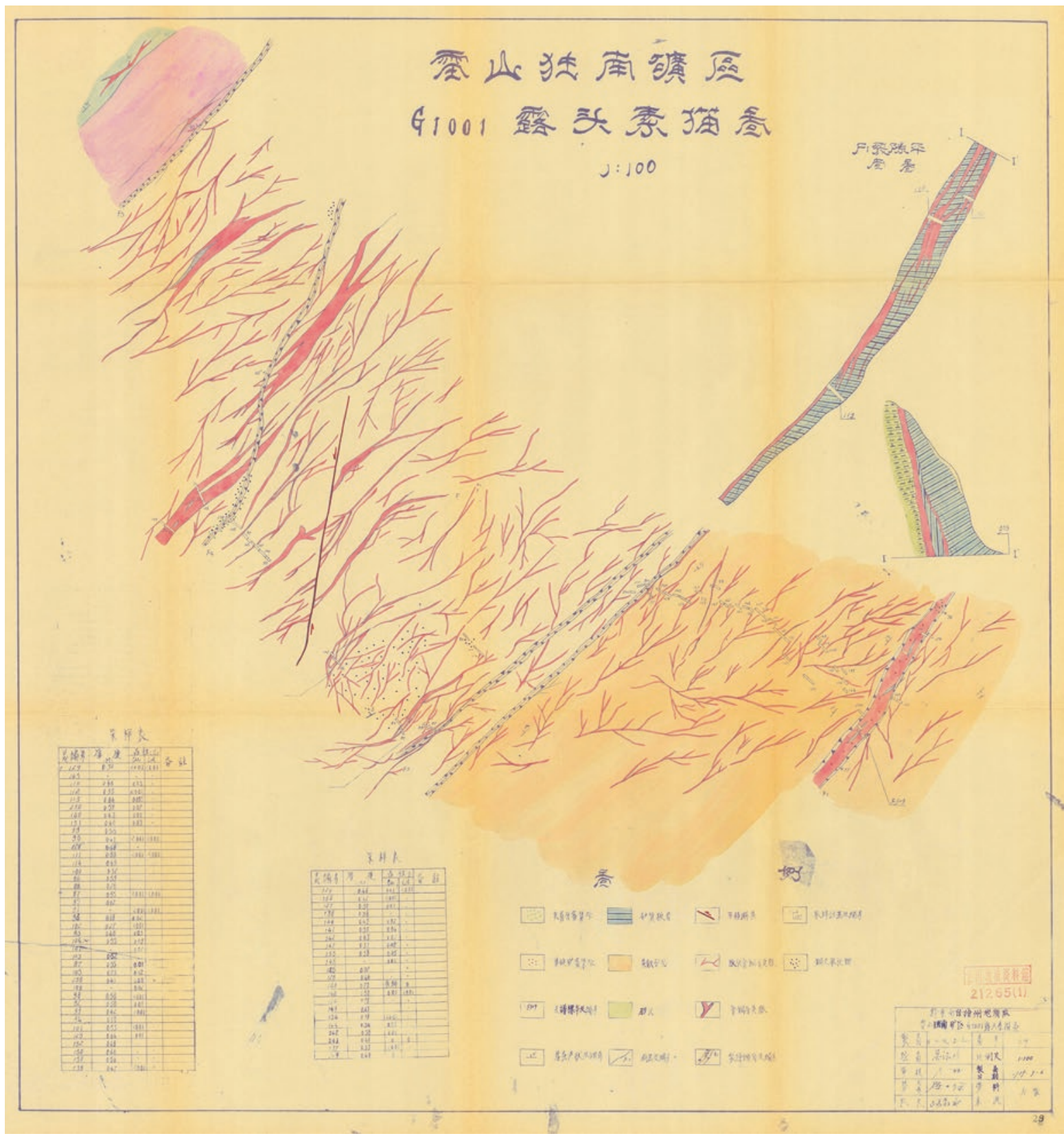

Fig. 4.28 Sketch of outcrop G1001 of the Dunan mining area of Leishan [28] 


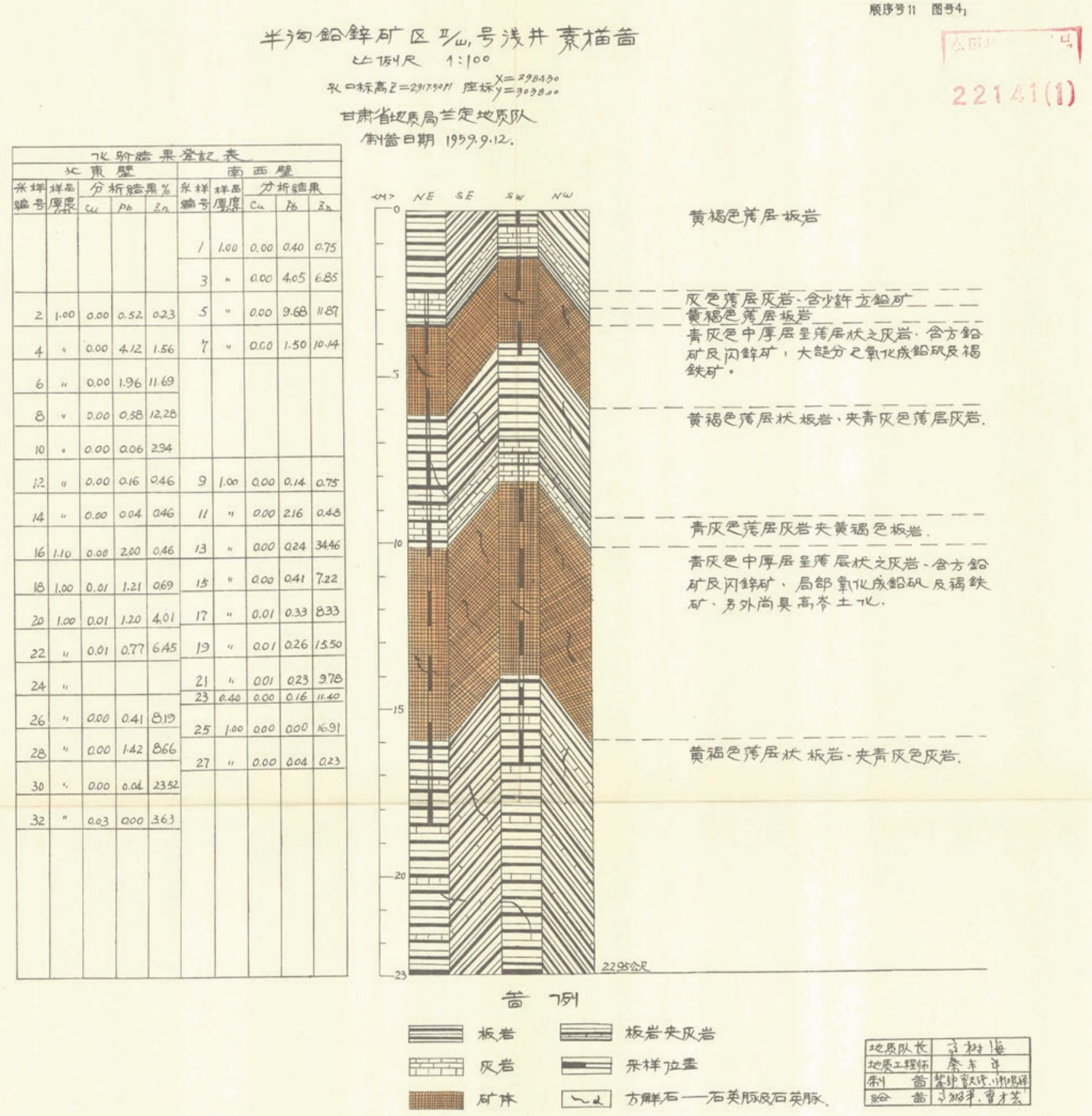

Fig. 4.29 Sketch of shallow well II/E1 of the lead-zinc mining area of Bangou [29] 
Fig. 4.30 Sketches of the interface of $\mathrm{J}_{3} \mathrm{a}$ and $\mathrm{J}_{2} \mathrm{c}$, among others [30]
图8 $\mathrm{J}_{3} \mathrm{a}$ 与 $\mathrm{J}_{2} \mathrm{C}$ 之接触面素描图

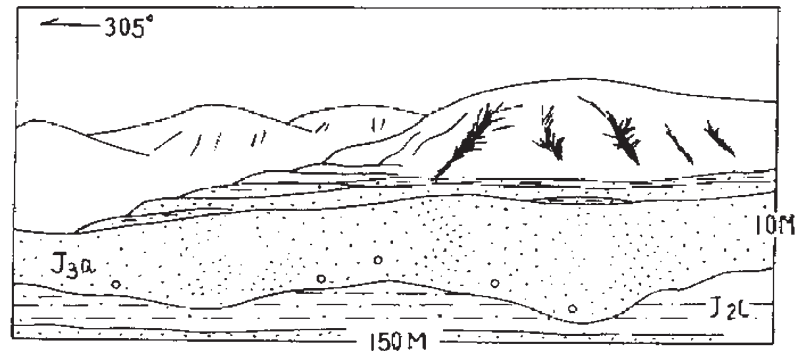

图9Cripliz+3与丁了接触面素描图

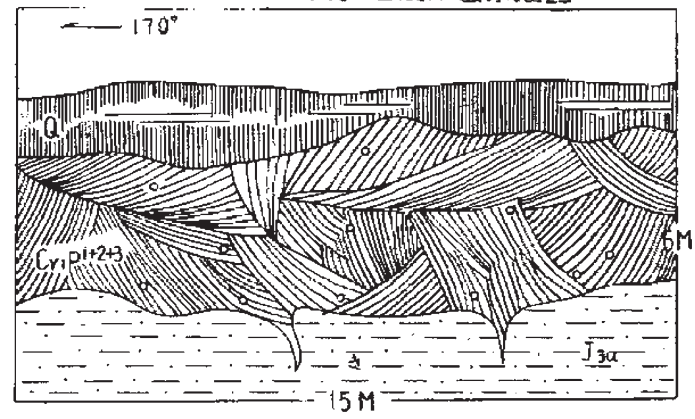

圈10 Cr, $\mathrm{P}^{4} 与 \mathrm{Cr}_{1} \mathrm{P}^{1+2+3}$ 之接

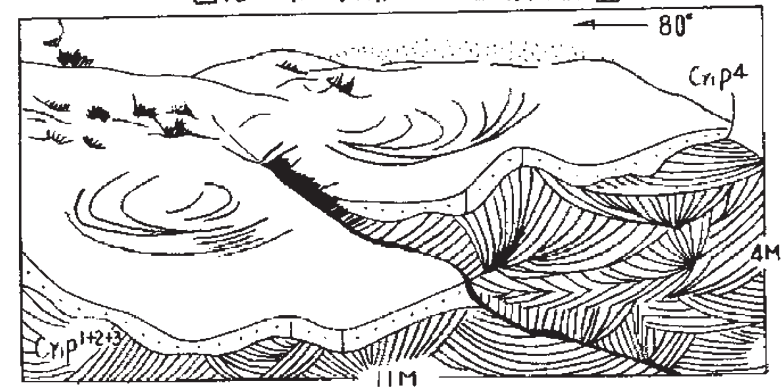




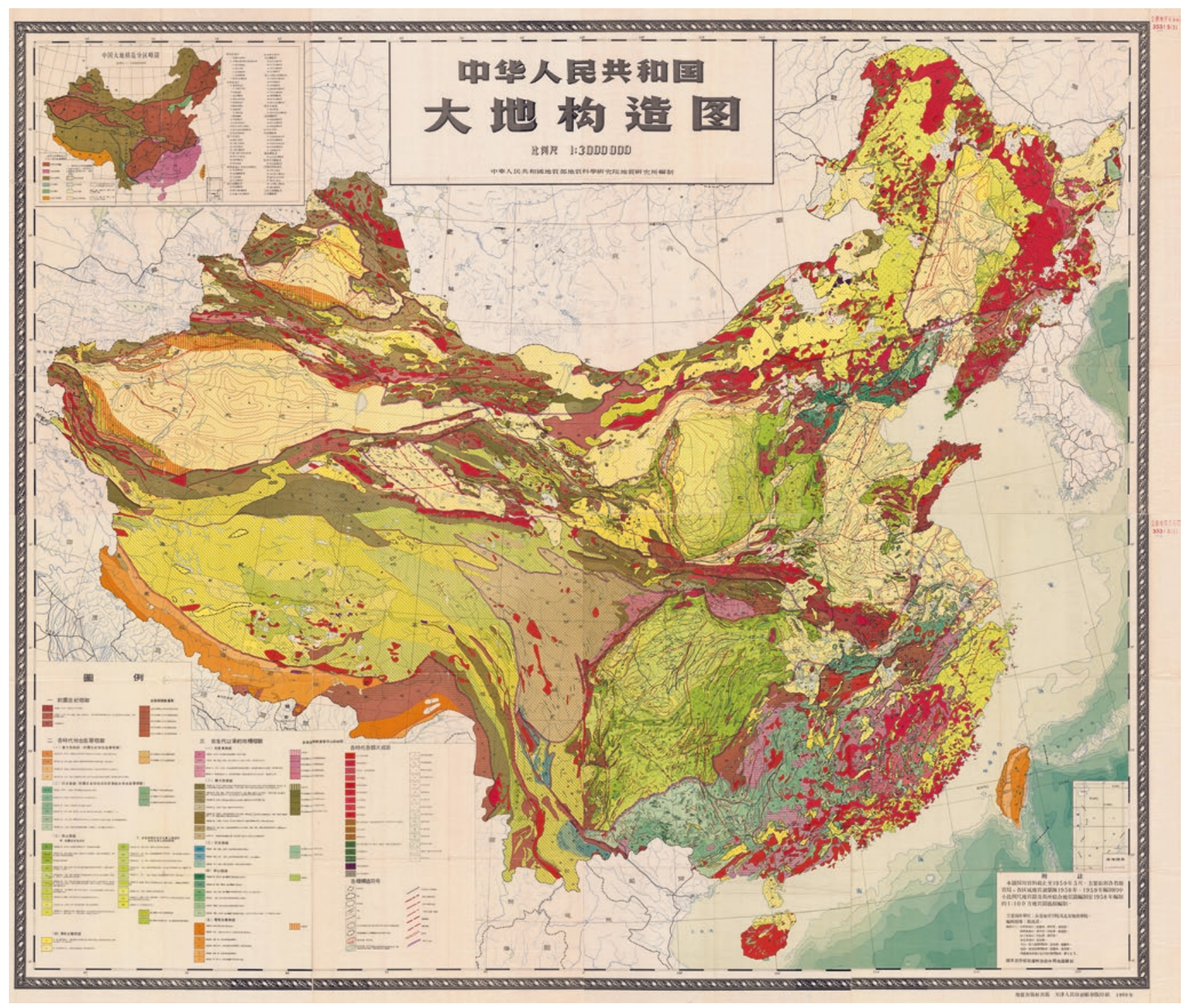

Fig. 4.31 Geotectonic map of the People's Republic of China [31] 


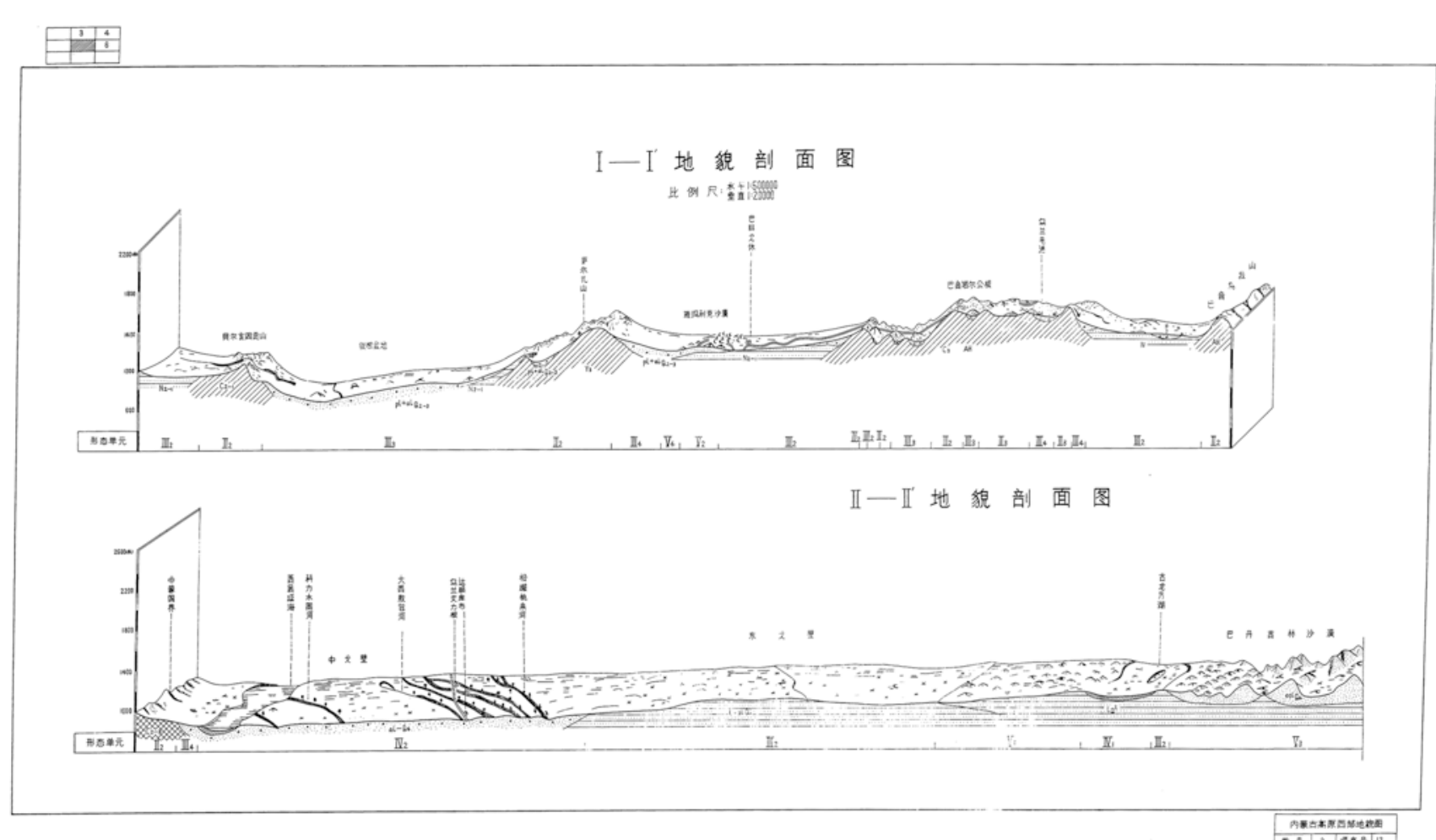

Fig. 4.32 Geomorphological map of the western Inner Mongolia Plateau (I-I', II-II' geomorphology sections) [32]

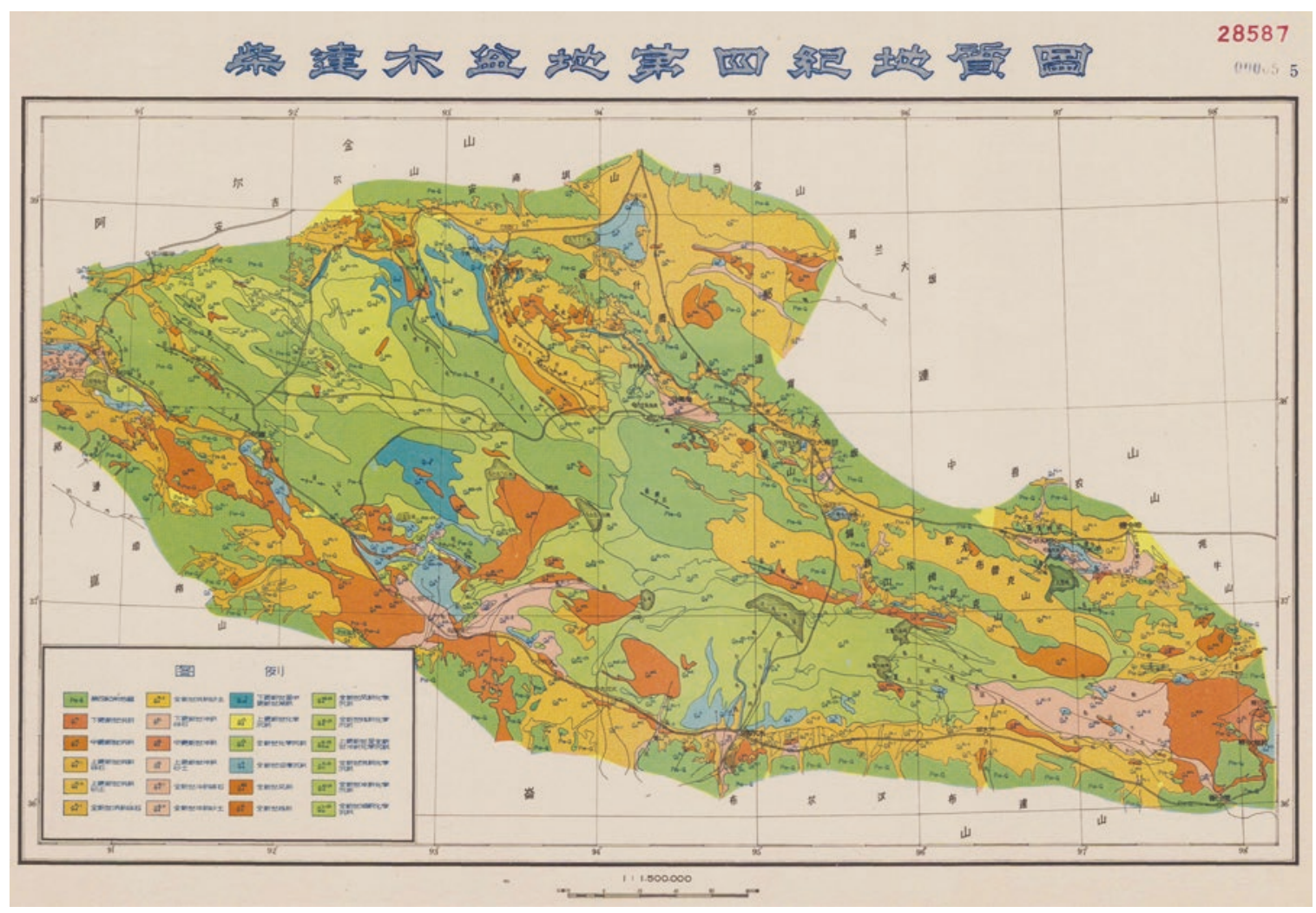

Fig. 4.33 Quaternary geological map of the Qaidam Basin [33] 
Fig. 4.34 Illustration attached to report on a tectonic fracture system and engineering geological issues of the dam area of the Xinfengjiang River [34]

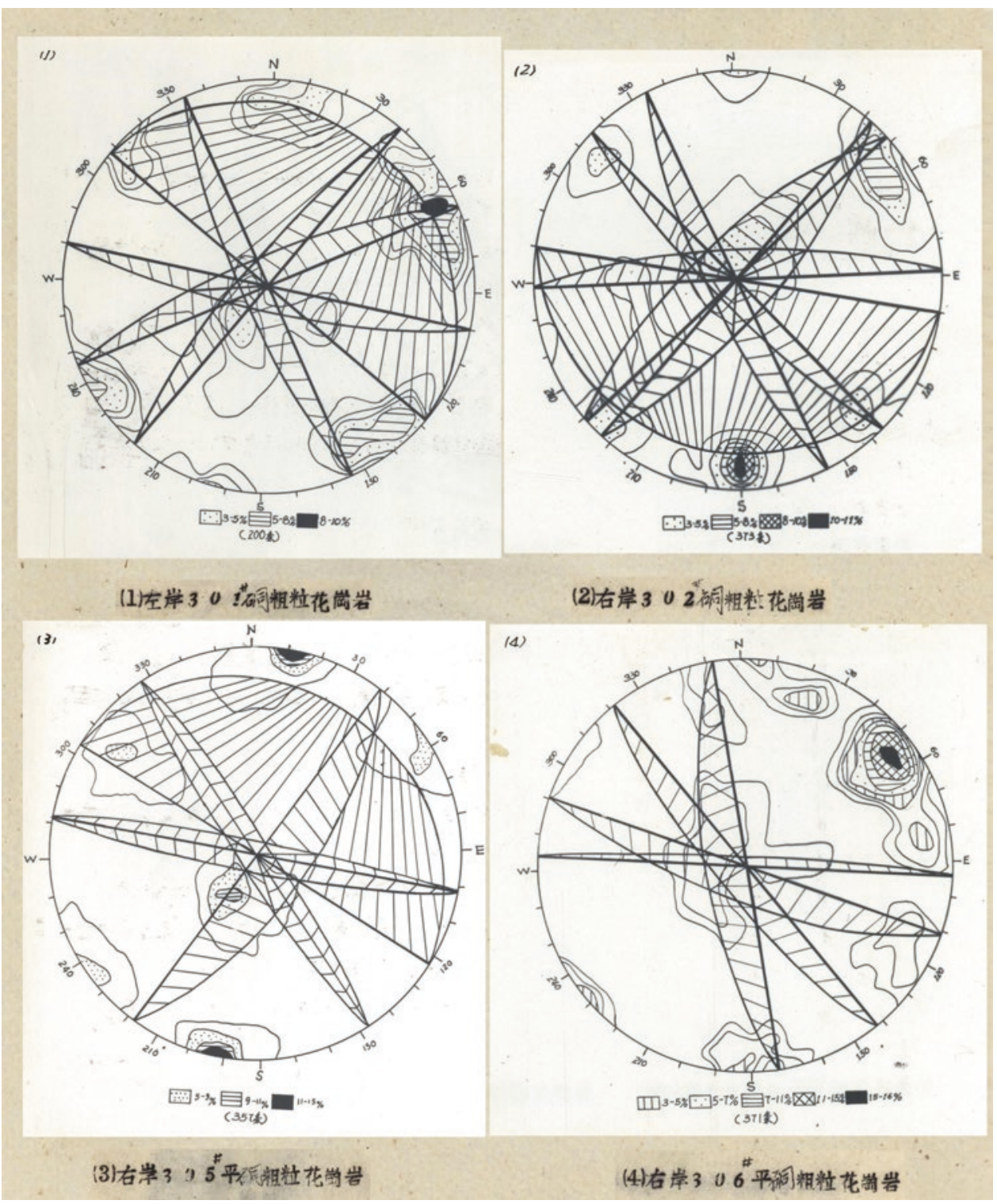




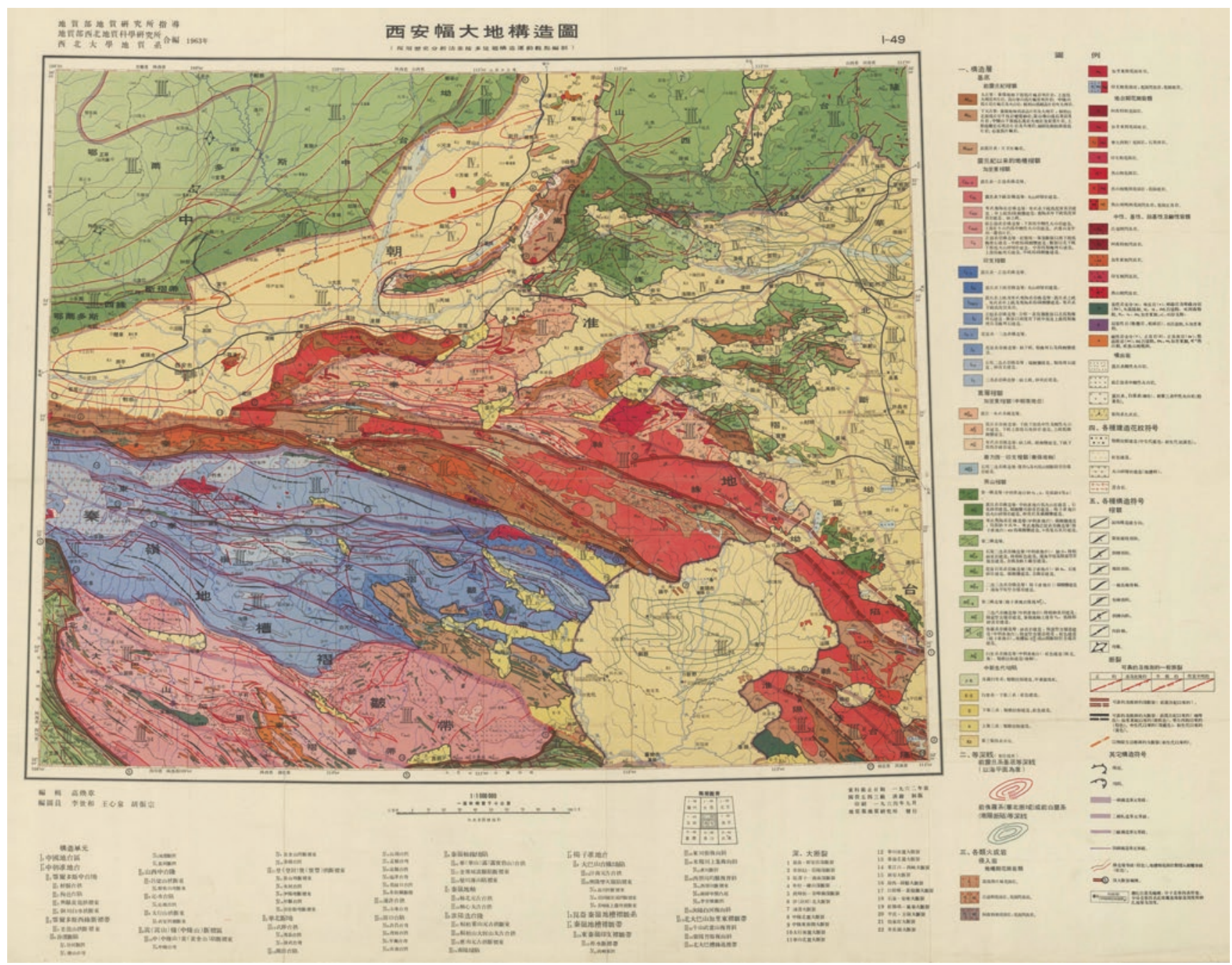

Fig. 4.35 Tectonic map of the Xi' an area [35] 


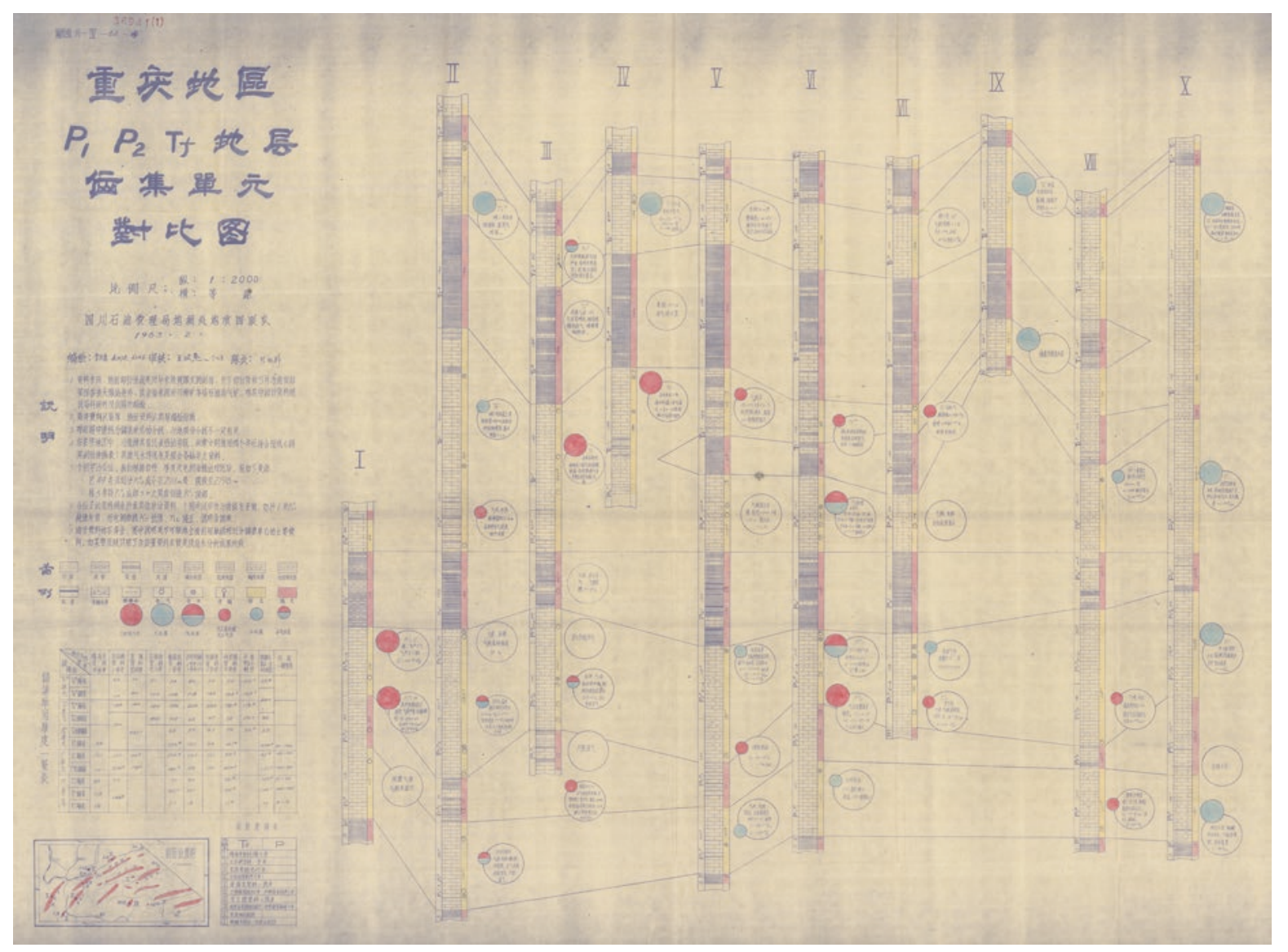

Fig. 4.36 Comparison of reservoir units of Strata $\mathrm{P}_{1}, \mathrm{P}_{2}$, and $\mathrm{T}_{f}$ in the Chongqing area [36] 


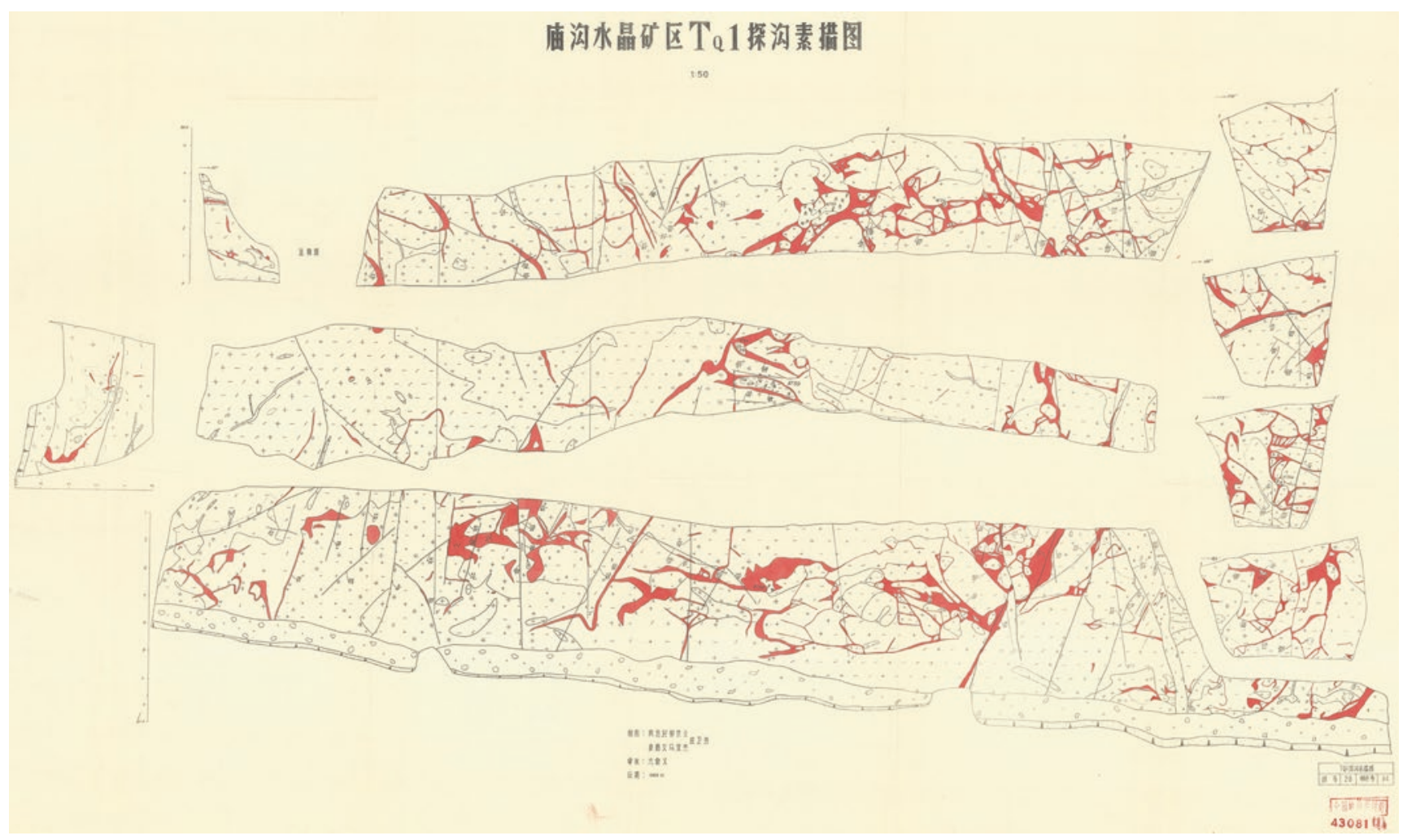

Fig. 4.37 Sketch of exploration ditch $\mathrm{T}_{\mathrm{Q}} 1$ at the crystal mining area of Miaogou [37] 
Fig. 4.38 Sketch of a geode in a mine block of the Gongli crystal mining area, Luodian County, Guizhou Province [38]

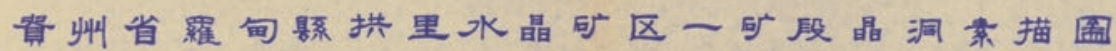

H $1: 5$

$90^{\circ}$

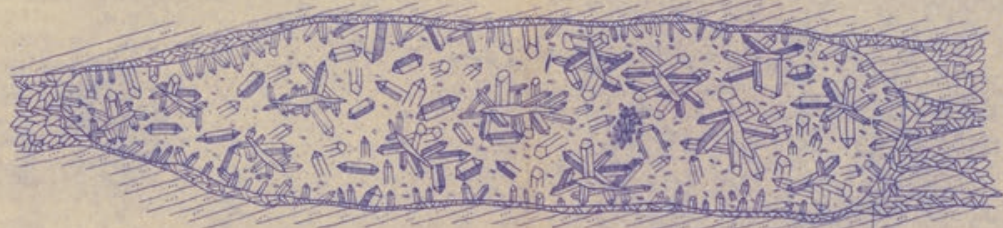

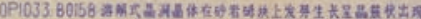

$\frac{1405}{13}$

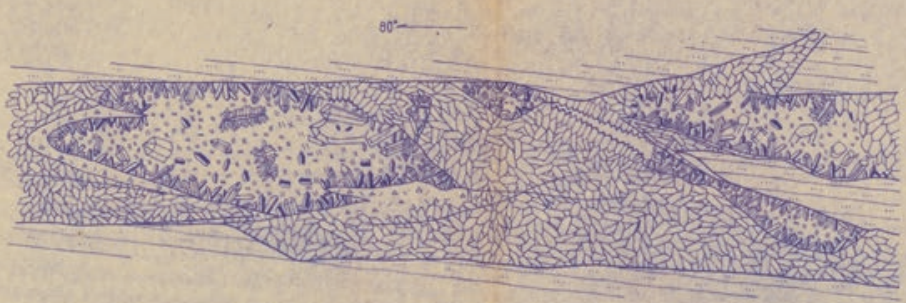

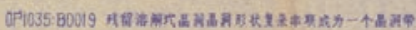

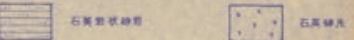

图

Q1) vene

83

"กลลำ

$\frac{1140}{19}$ 5omes

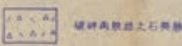

例

1,0 *as. 


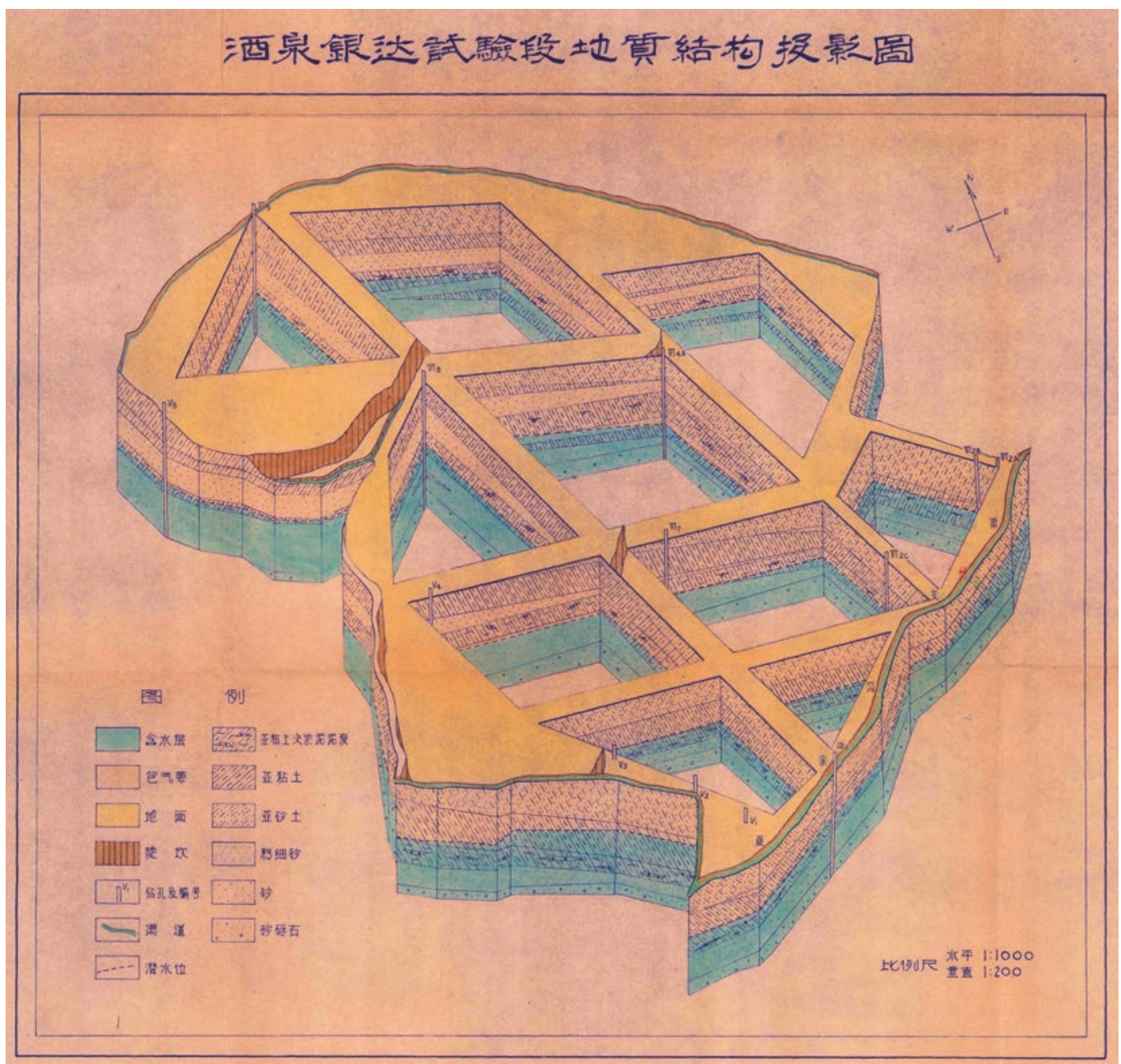

Fig. 4.39 Geological structure projection diagram of the Yinda experimental section of Jiuquan [39] 


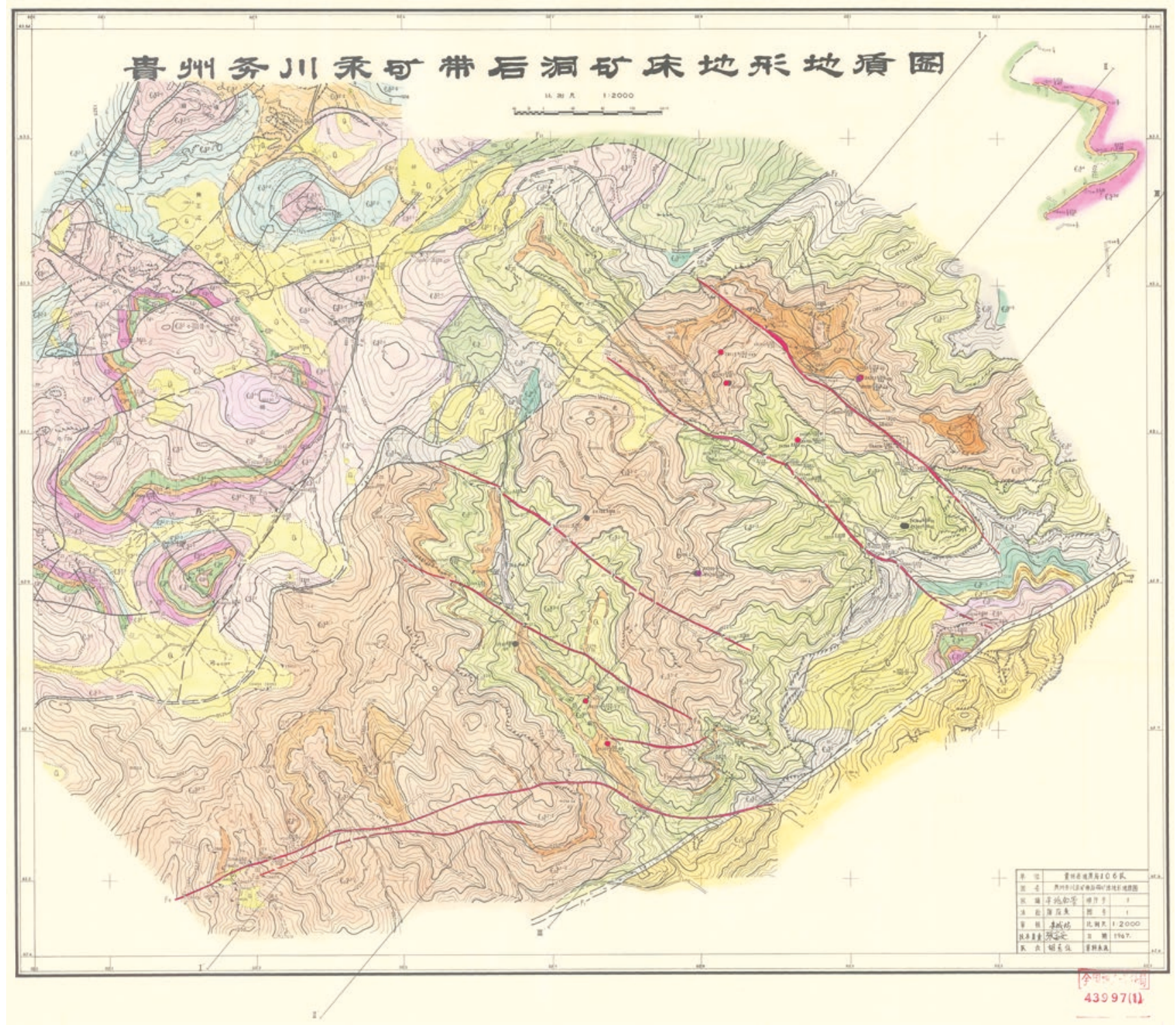

Fig. 4.40 Geomorphological and geological map of the Houdong mineral deposit in the Wuchuan mercury mining belt, Guizhou Province [40] 


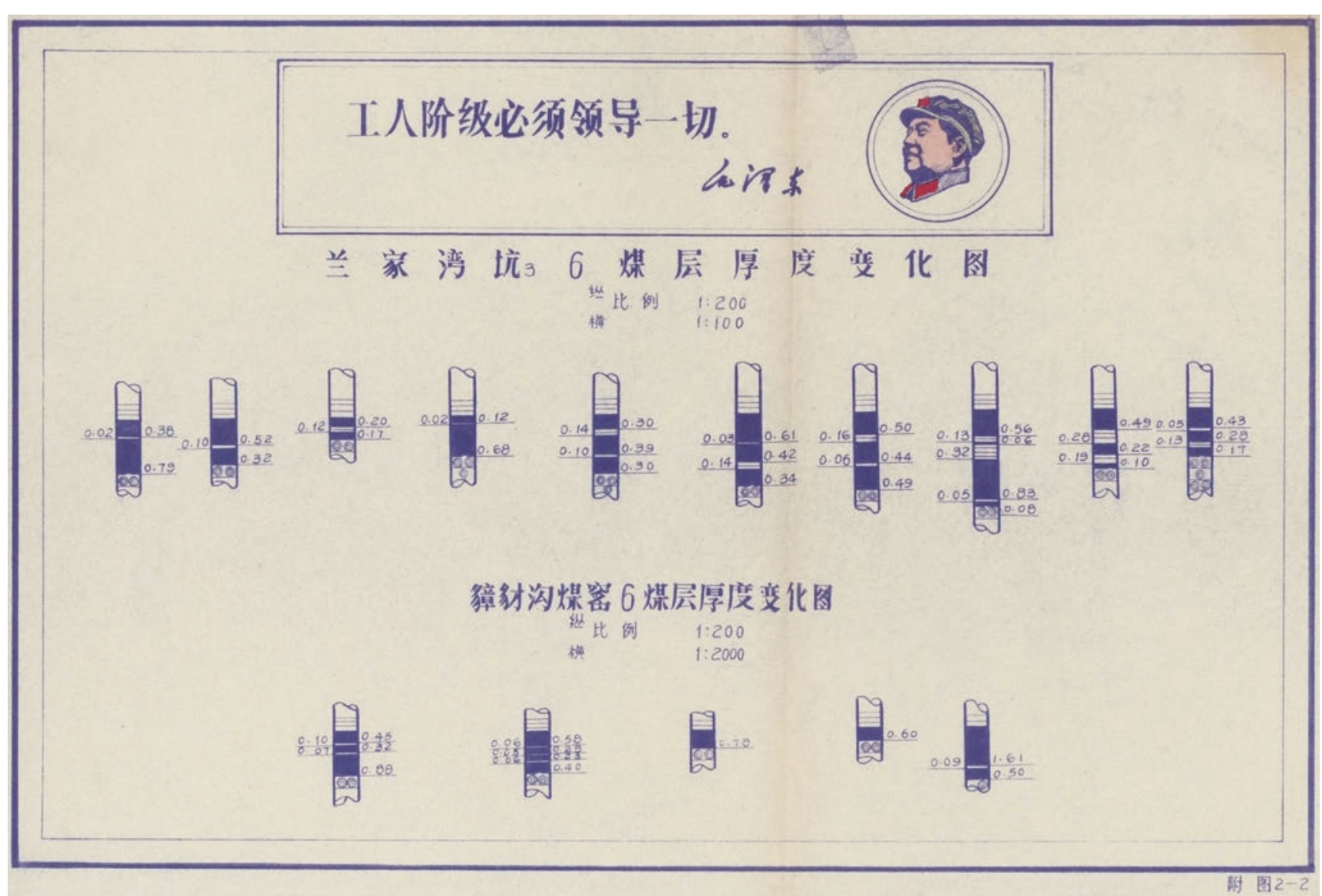

Fig. 4.41 Diagram of coal seam thickness variation of Pit 36 in Lanjiawan [41] 


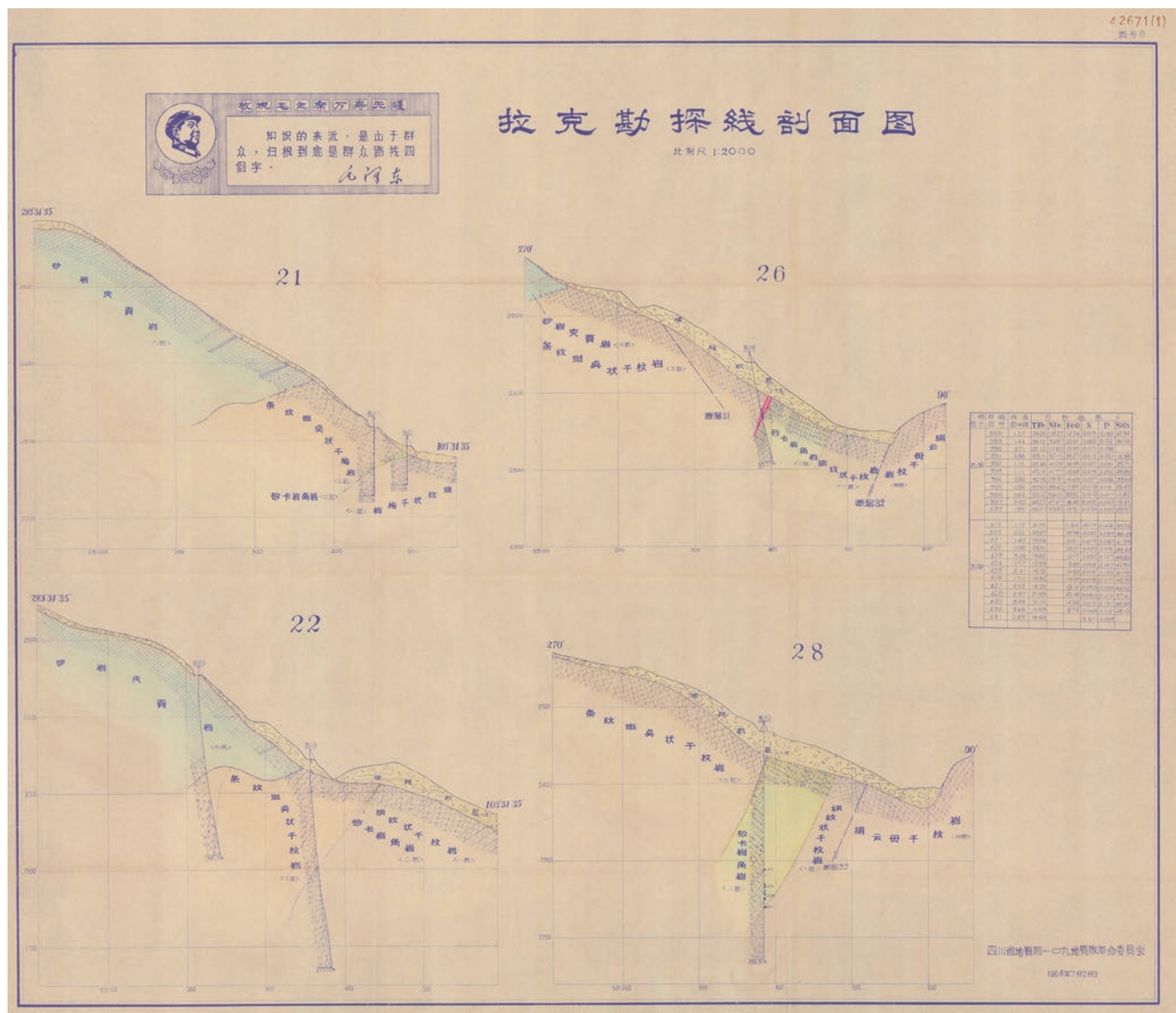

Fig. 4.42 Profile diagram of lake exploration line [42] 
Fig. 4.43 Joint contour map for the report of the 1963 general survey on the Qitianling area of Hunan Province [43]

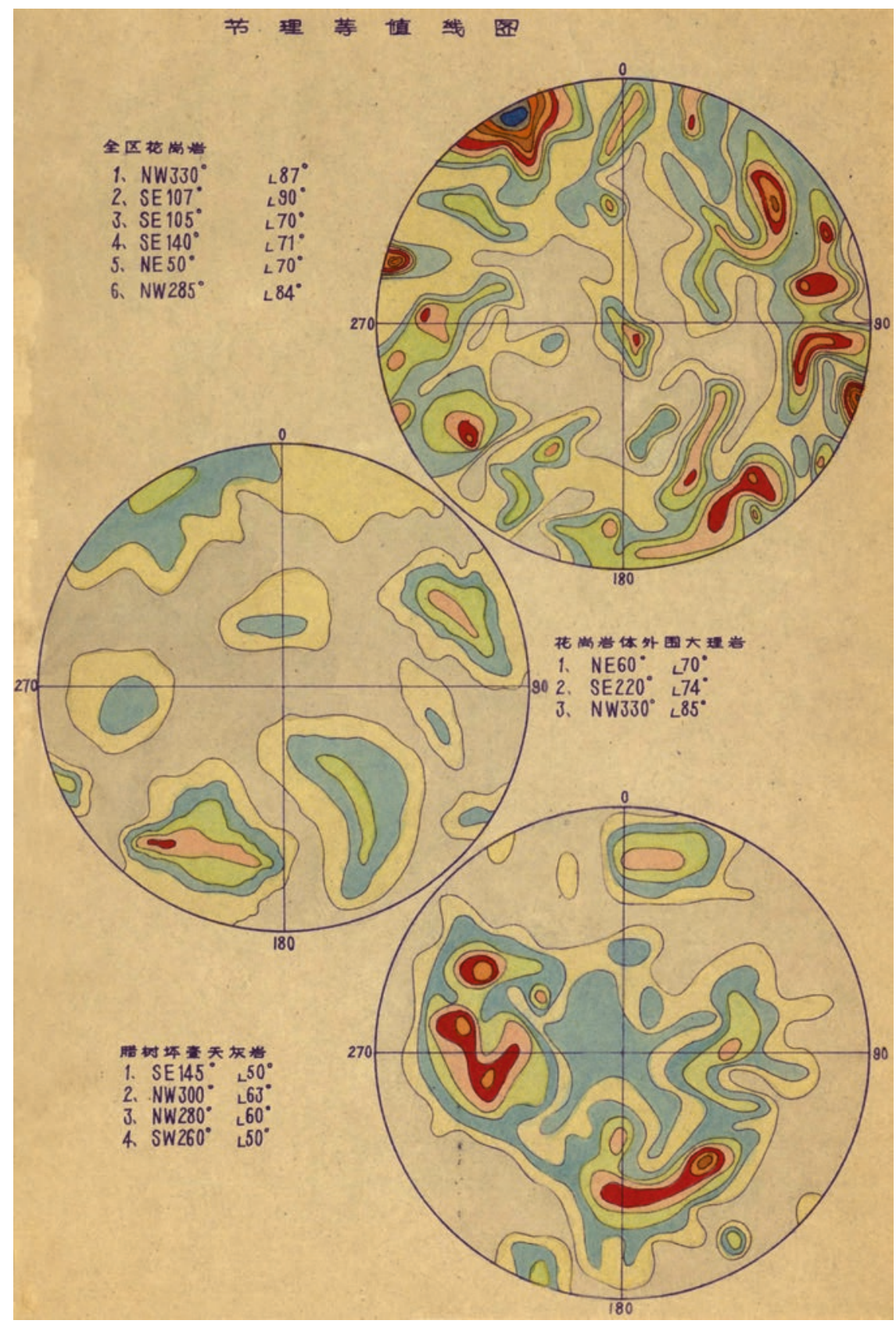




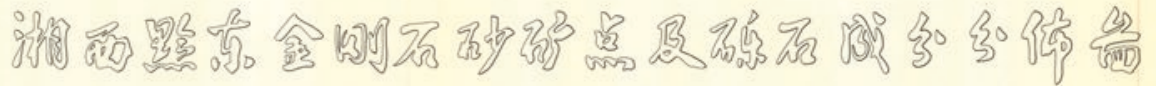
O, in is 10 acom

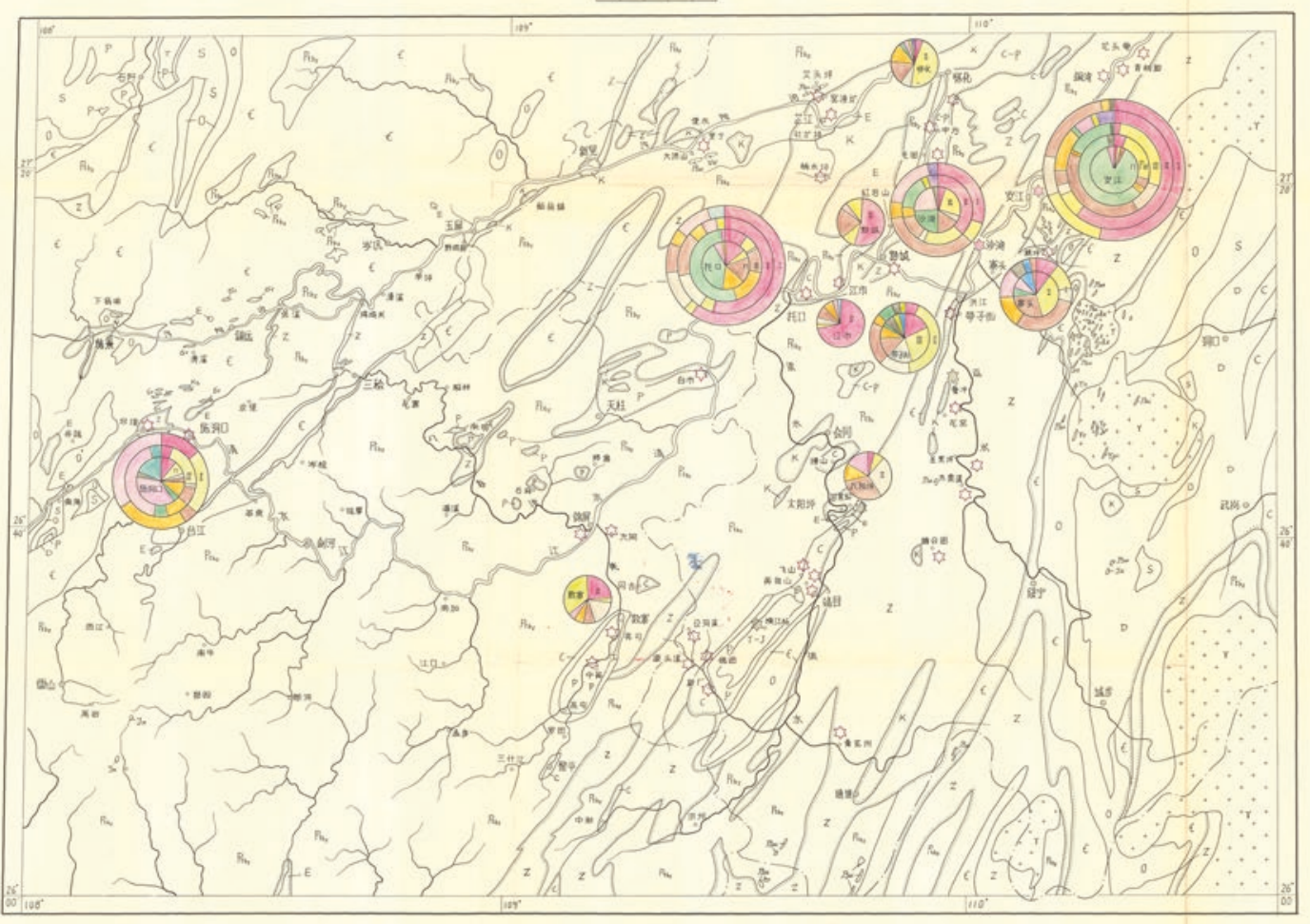

園例

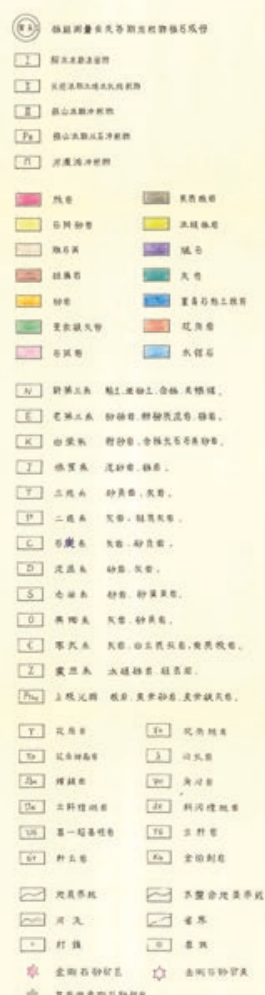

Fig. 4.44 Diagram of the composition and distribution of the diamond deposit in eastern Guizhou Province and western Hunan Province [44] 


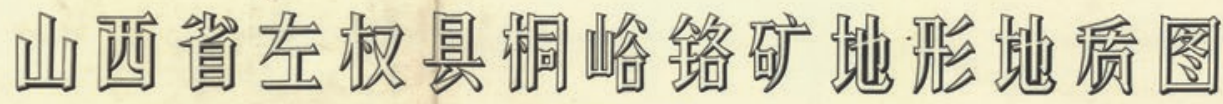

比例尺 1:1000
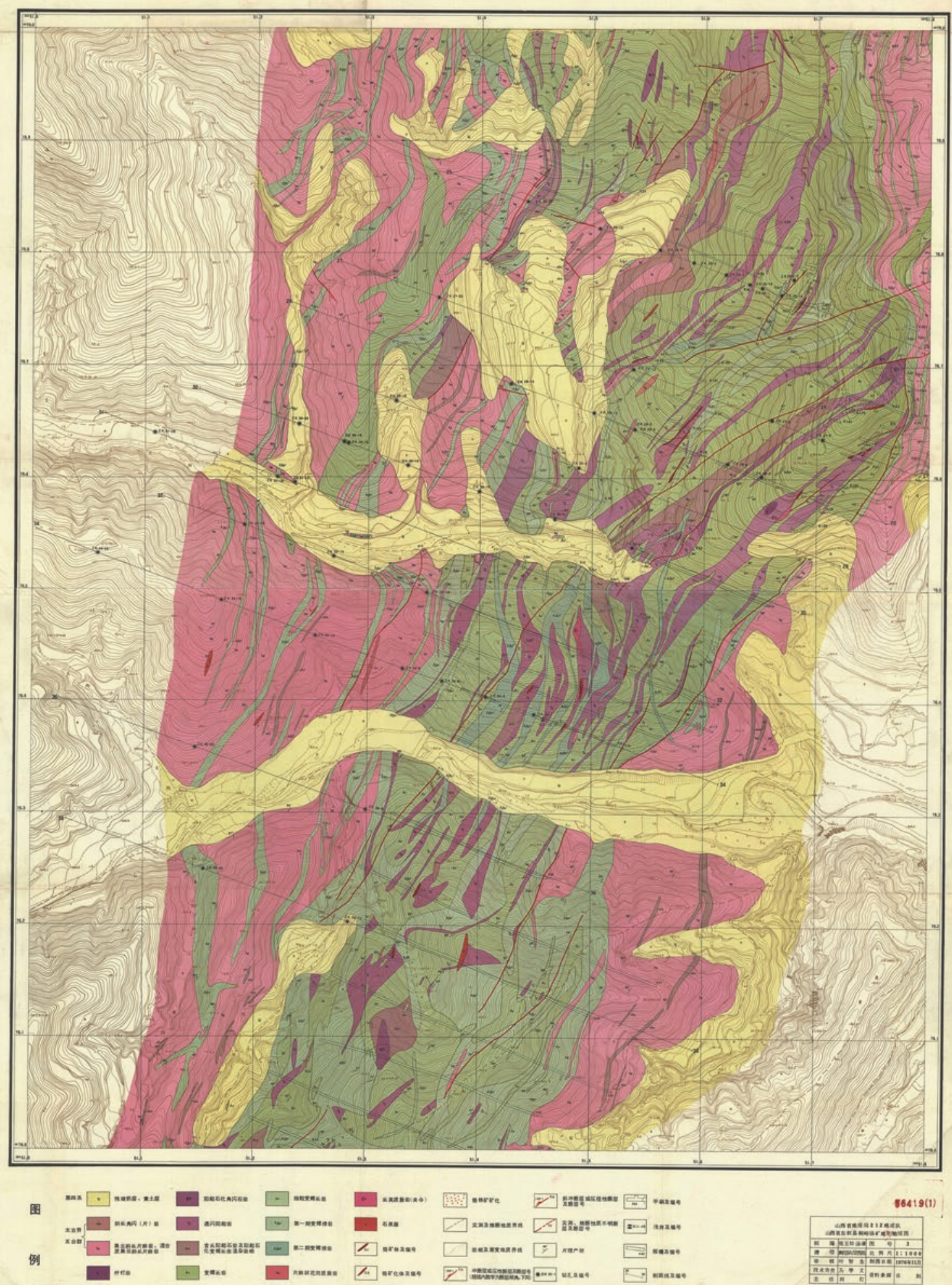

Fig. 4.45 Topographic and geological map of Tongyu chrome mine in Zuoquan County, Shanxi Province [45] 


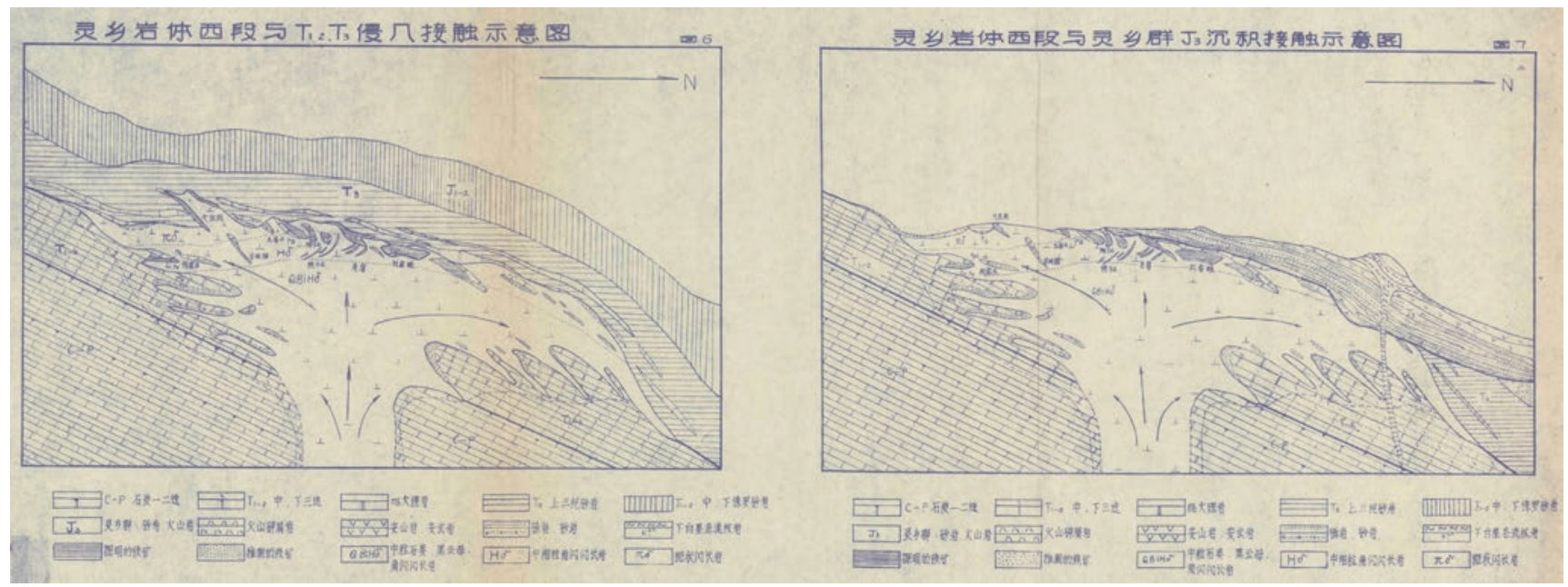

Fig. 4.46 Schematic diagram of the intrusion of $T_{1,2}$ and $T_{3}$ in the western section of the Lingxiang rock mass, etc. [46] 
Fig. 4.47 Hypothetic diagram of the development stage of volcanic subsidence of the Lujiang-Zongyang volcanic basin [47]

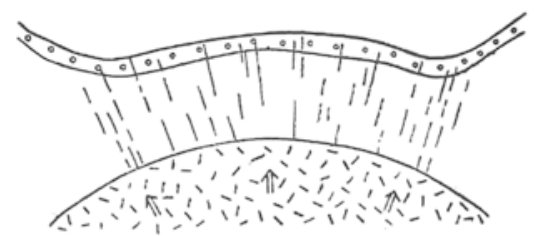

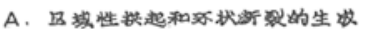

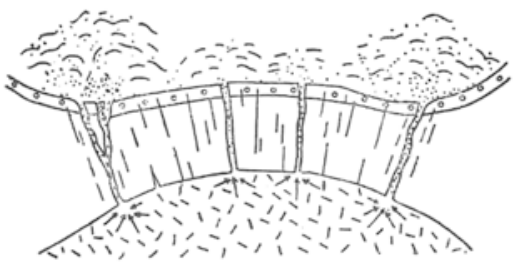

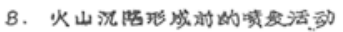

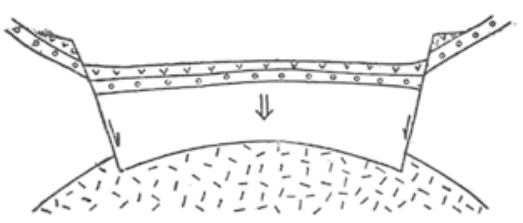

c. 沉榢作用一火山沉的形成。

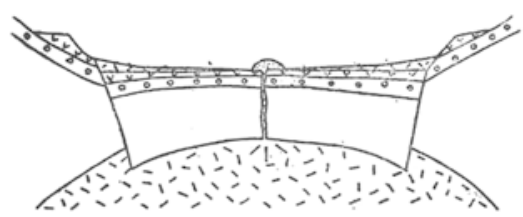

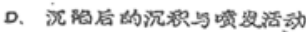

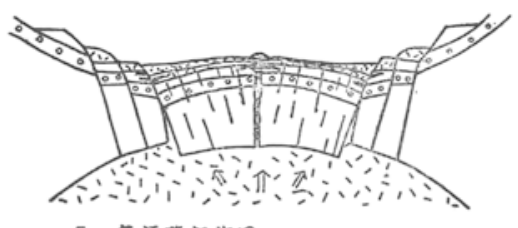

E、算活登起作间
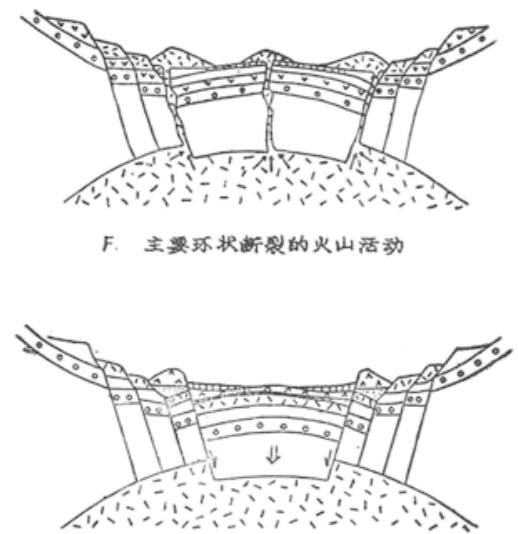

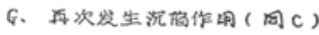

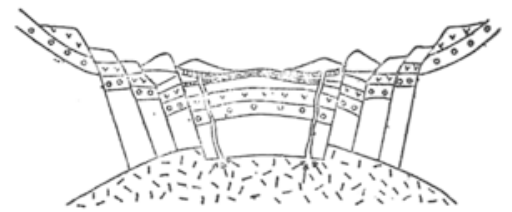

H、海陷后的火山活动 (同D)

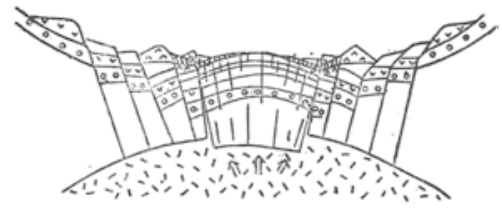

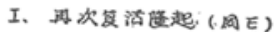

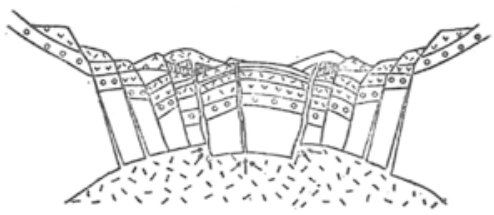

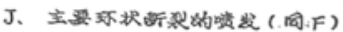

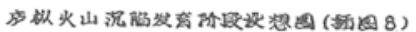

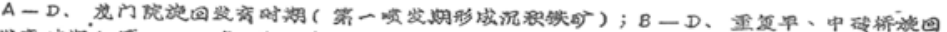

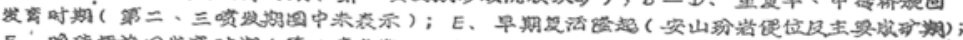

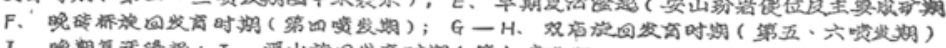

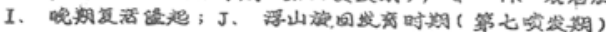

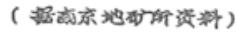




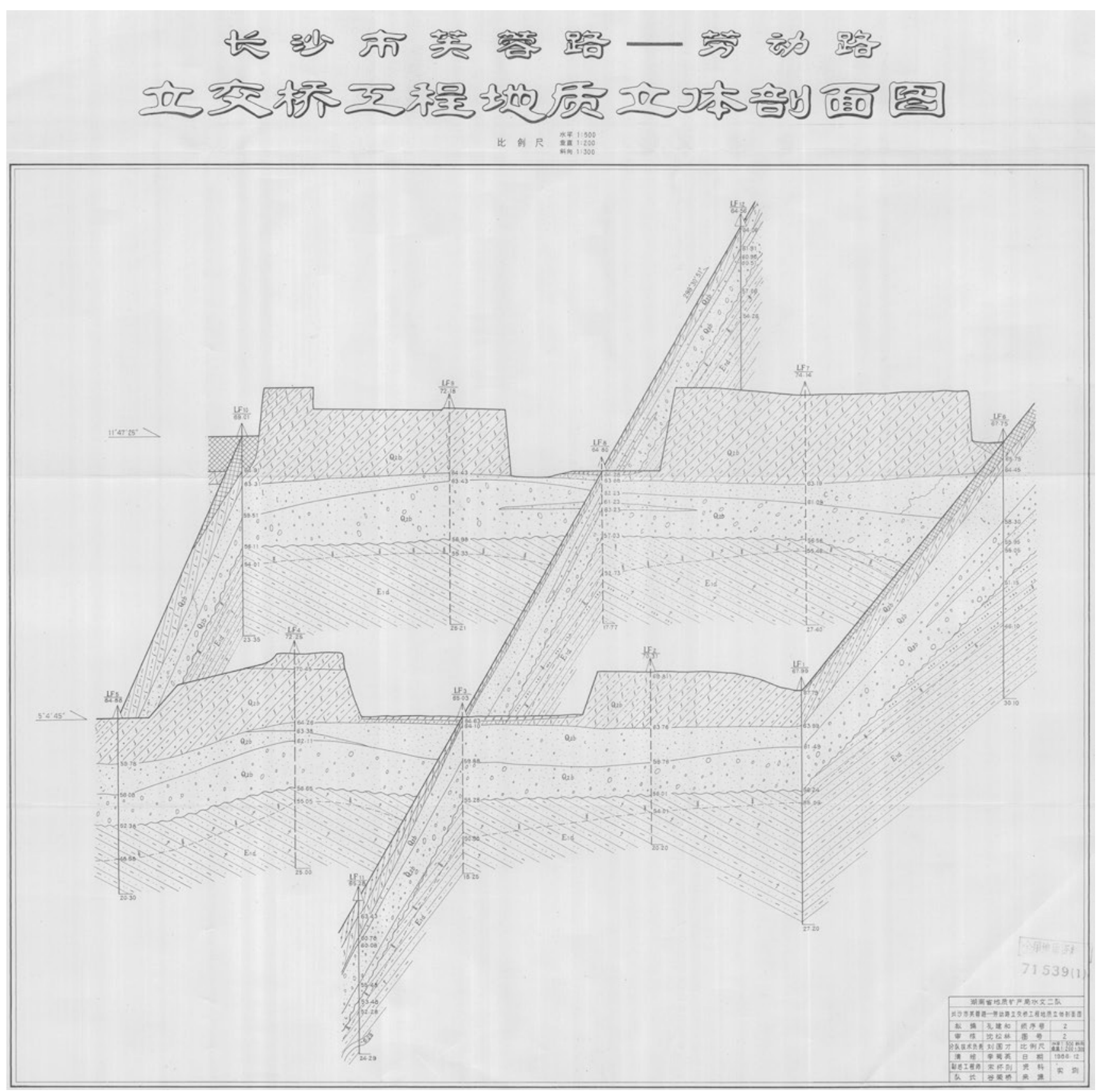

Fig. 4.48 Sectional axonometric drawing of engineering geology of the Fuling Road-Labor Road Overpass Project [48] 
Fig. 4.49 Illustrations and sketches of minerals attached to report on geological turquoise survey at Mt.

Duancen, Wulan County,

Qinghai Province [49]

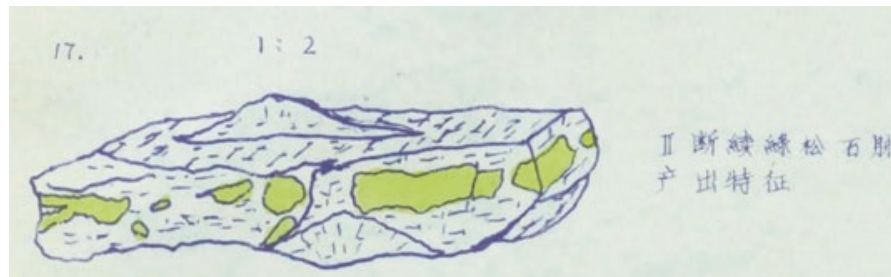

18.

$1: 2$

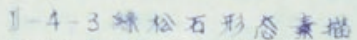

If t

梳石过没的特

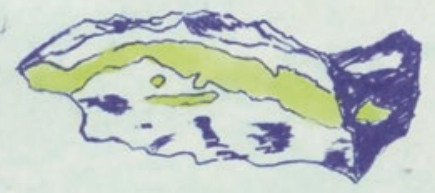

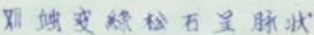

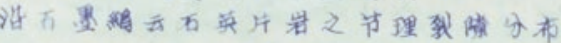

19. i: 50

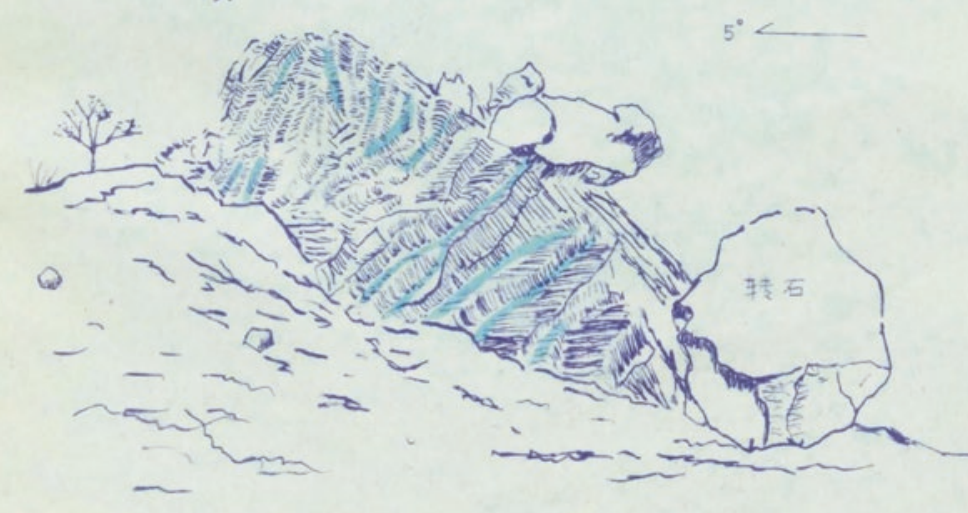




\section{卓新县温头堂子矿区血号伟晶岩脉坑壁素描图}

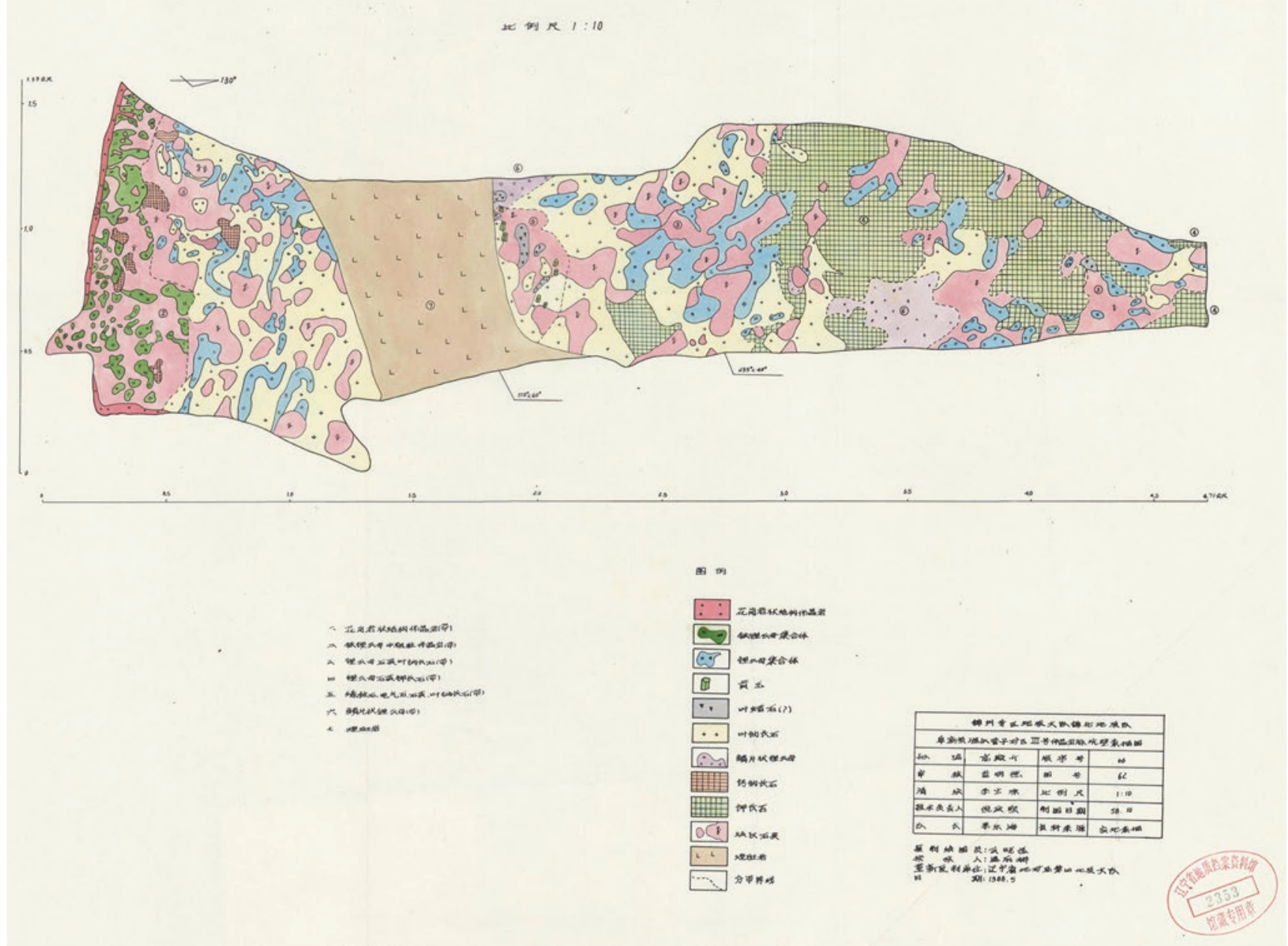

Fig. 4.50 Sketch of gallery wall of the No. 3 pegmatite vein in Wentouyingzi minefield, Fuxin County [50] 


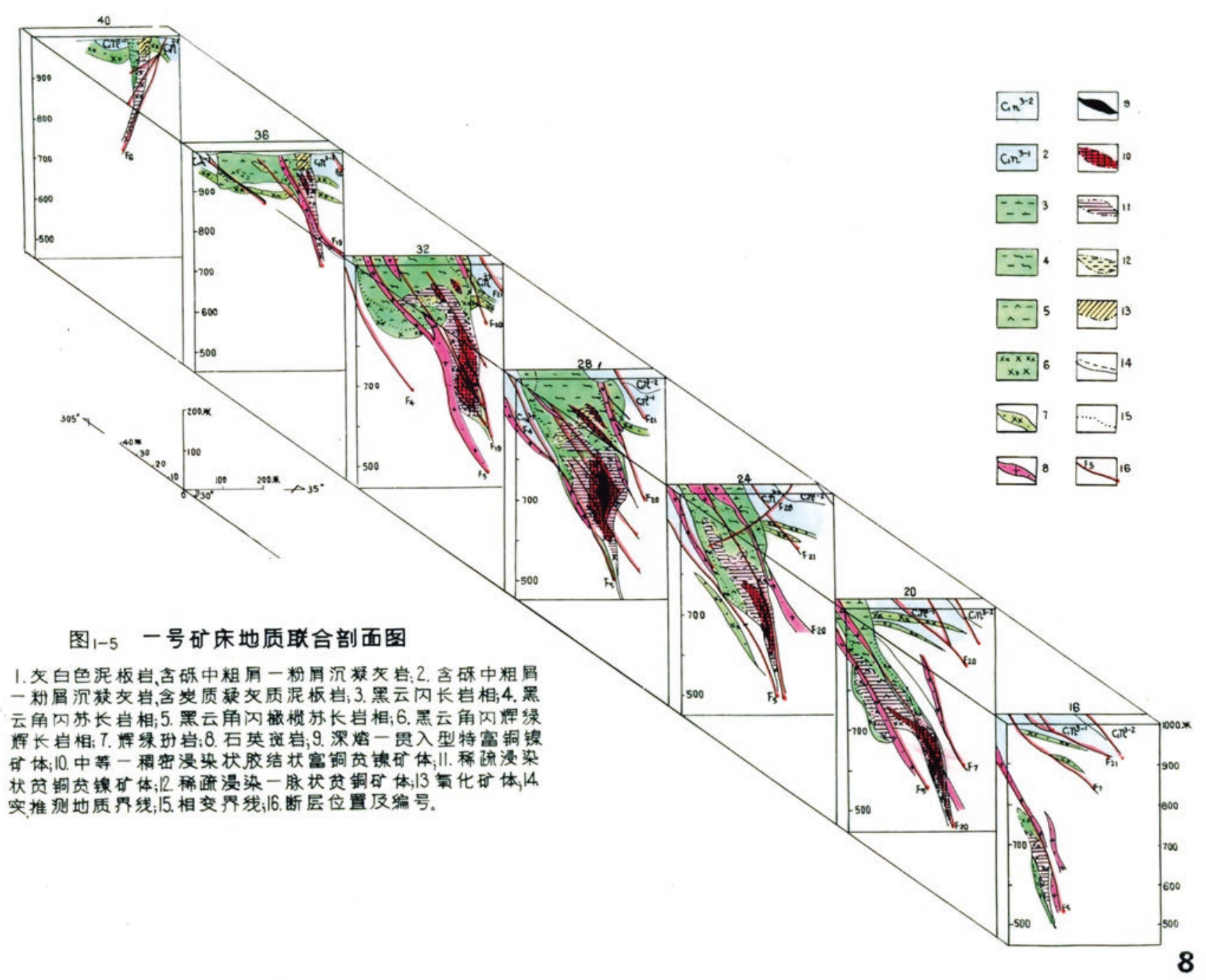

Fig. 4.51 Geological joint section of No. 1 deposit [51] 


\section{广东省汕头地区城市区域物化探工区}

\section{钒元素地球化学 图}

1:100000

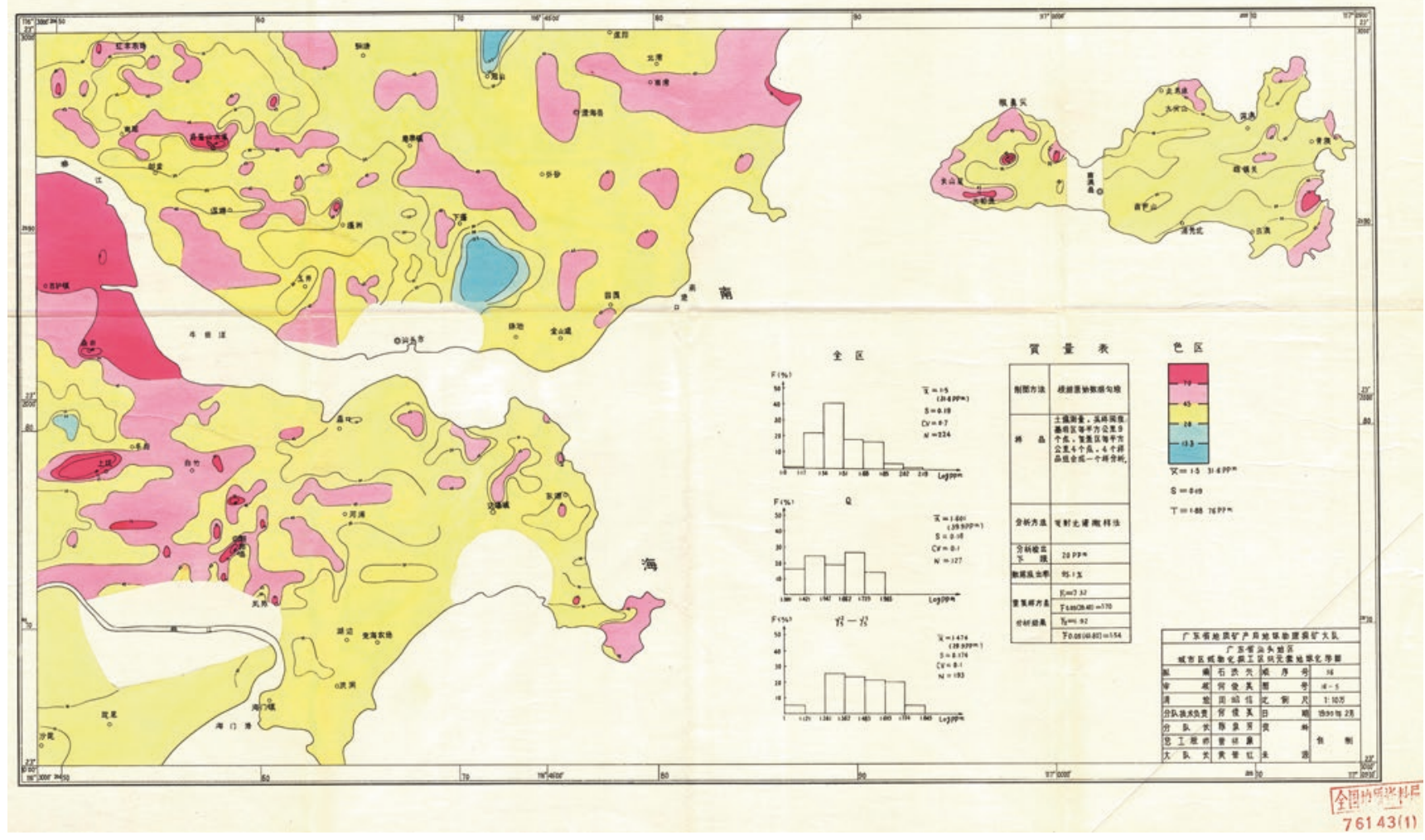

Fig. 4.52 Geochemical map of vanadium in the geochemical exploration site of an urban area of Shantou City, Guangdong Province [52] 


\section{浙江省椒江市规划区工程地质剖面图}

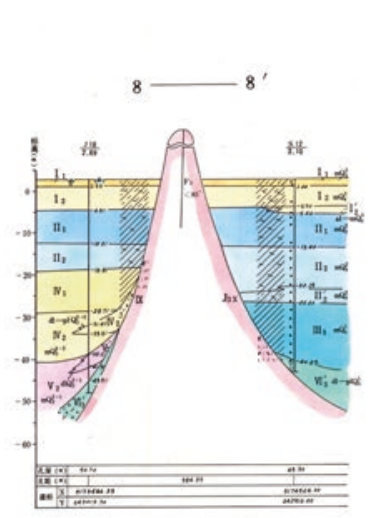

比例尺: 水平1:10000 重直 $1: 500$

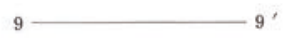

$10 \longrightarrow 10^{\prime}$
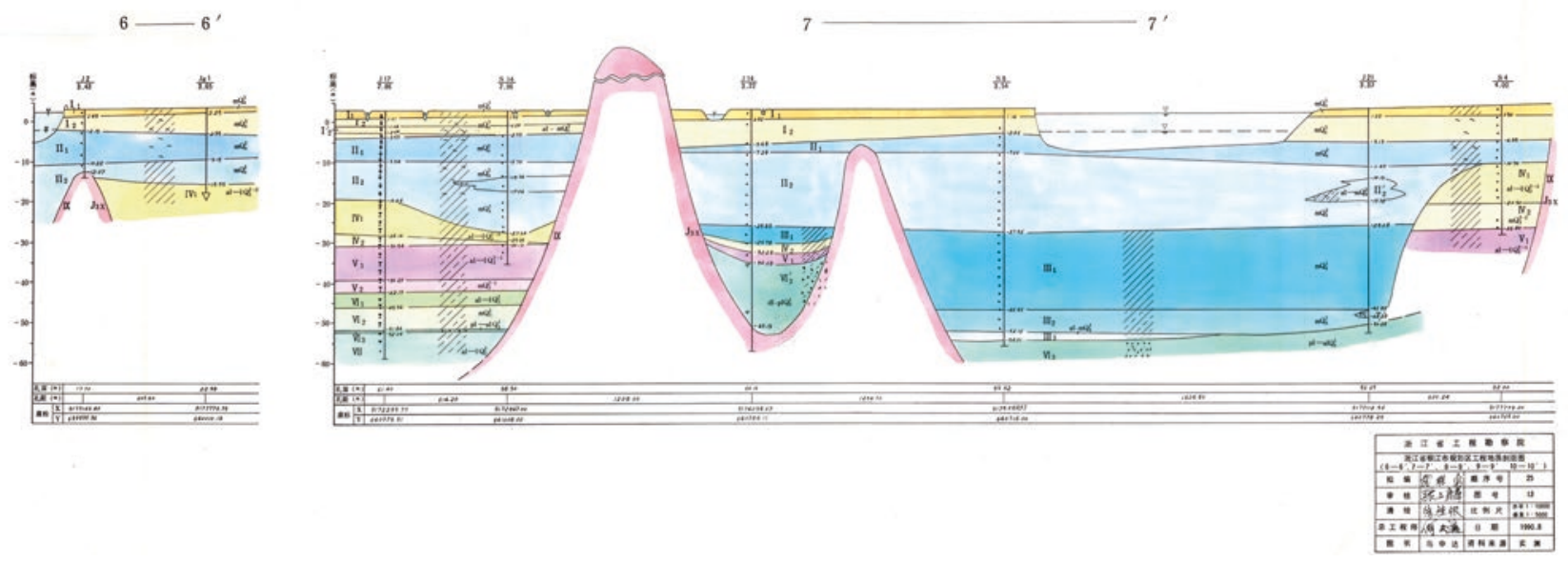

Fig. 4.53 Engineering geological profile of district planning of Jiaojiang City, Zhejiang Province [53] 


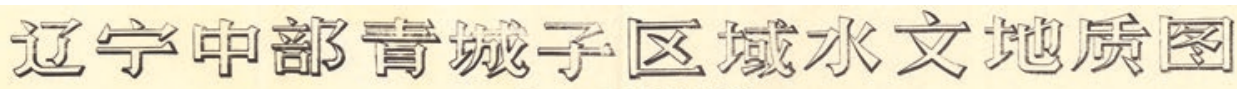

\section{距於 1:100000}

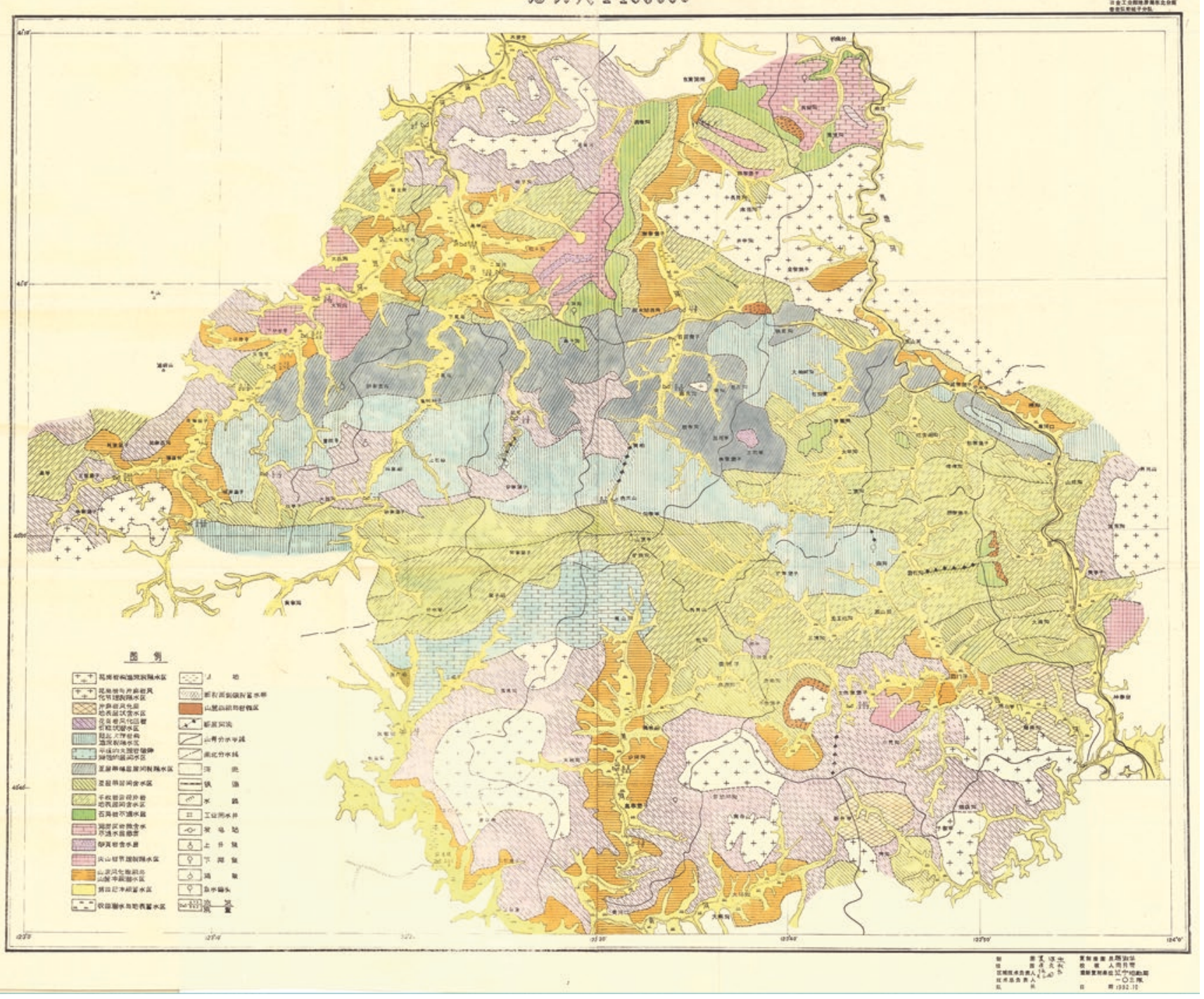

Fig. 4.54 Hydrogeological map of the Qingchengzi region in central Liaoning Province [54]

\section{References}

1. Geological Exploration Company of the Central South Branch of the China Nonferrous Metals Management Bureau. Geomorphological sketch of Shirenfeng Tungsten Mine, Shixing, Guangdong Province, (Sheet 1). 1954. doi: https://doi.org/10.12063/data.O.2018. NGA7933.T1.141.1.

2. Geological Exploration Company of the Central South Branch of China Nonferrous Metals Administration Bureau. Geomorphological sketch of Shirenfeng Tungsten Mine, Shixing, Guangdong, (Sheet 1). 1954. doi: https://doi.org/10.12063/ data.O.2018.NGA7933.T1.142.1.

3. Geological Exploration Company of the Central South Branch of China Nonferrous Metals Administration Bureau. Geomorphological sketch of Shirenfeng Tungsten Mine, Shixing, Guangdong, (Sheet 2). 1954. doi: https://doi.org/10.12063/ data.O.2018.NGA7933.T1.144.1.
4. The $625^{\text {th }}$ exploration team of the Northwest Geological Bureau. Diagram of a seam columnar section of Yaojie Coal Mine. 1954. doi: https://doi.org/10.12063/data.B.2018.NGA3842.T1.2.1.

5. Engineering Geology Team of Nanjing University. Schematic diagram of the engineering geological map of areas south of the dam axis (river bed section). 1954. doi: https://doi.org/10.12063/ data.D.2018.NGA8754.T1.17.1.

6. Chu Boyi. Geological map of areas peripheral to Gaositai, Chengde, Rehe. 1954. doi: https://doi.org/10.12063/data.A.2018.NGA8904. T1.2.1.

7. Xue Jiaquan. Equal area chart of the Middle Jurassic Stratum of Yaojie Coal Mine in the Minhe Basin. 1954. doi: https://doi. org/10.12063/data.O.2018.NGA8946.T1.21.1.

8. Yellow River Planning Commission. Agricultural utilization map of irrigated land in the Yellow River Basin. 1954. doi: https://doi. org/10.12063/data.O.2018.NGA9174.T1.9.1.

9. Huaihe River Commission of the Ministry of Water Resources Governance. Distribution of observation stations at various lev- 
els in the Huaihe River Basin in 1954. 1954. doi: https://doi. org/10.12063/data.D.2018.NGA9641.T1.1.1.

10. Liu Hongxi. Topographic sketch of the Ningjiahe River Dam, Shawan County. 1955. doi: https://doi.org/10.12063/data.O.2018. NGA3870.T1.52.1.

11. Tian Zhengfang. Diagram of a continuous columnar section of Tuozu Iron Ore Mine in Butuo County. 1955. doi: https://doi. org/10.12063/data.C.2018.NGA9919.T1.15.1.

12. Gao Lingyun. Geological profile sketch of Mt. Guaran-Mt. Yinshan. 1955. doi: https://doi.org/10.12063/data.A.2018.NGA9957.T1.3.1.

13. Geological Survey Department of Xinjiang Petroleum Corporation, Ministry of Petroleum Industry. Sketch attached to final geological report on Subashi in central Mt. Huoyan, the Turpan Basin. 1955. doi: https://doi.org/10.12063/data.O.2018.NGA10591.T1.23.1.

14. Liu Yanwen. Statistical diagrams of joints and fissures of the Tuanbaoshan Lead-Zinc Mining Area in Hanyuan County, Sichuan Province. 1955. doi: https://doi.org/10.12063/data.O.2018. NGA2596.T1.72.1.

15. Cao Yanzuo. Sectional diagram of a copper mine in the adjoining area of Yimen, Shuangbai, and Eshan Counties, Yunnan Province. 1956. doi: https://doi.org/10.12063/data.A.2018.NGA9903. T1.157.1.

16. Xiong Mingying. Topographic and geological profile of Tuozu Iron Ore Mine in Butuo County. 1956. doi: https://doi.org/10.12063/ data.C.2018.NGA9919.T1.17.1.

17. Liang Zhongjiang. Perspective view of the terrain in the vicinity of Maoming Oil Shale Field. 1956. doi: https://doi.org/10.12063/ data.O.2018.NGA9976.F1.3.1

18. State-owned, locally administered Liaoning Mining Company. Microscopic illustration attached to calculation table of a talc reserve in Fanjiapuzi. 1957. doi: https://doi.org/10.12063/ data.O.2018.NGA11503.T1.75.1.

19. Cai Jianjie. Perspective diagram of ore bodies near West Lake. 1957. doi: https://doi.org/10.12063/data.C.2018.NGA11926.T1.68.1.

20. Zhou Mingfen. Engineering geological map of pyrite mine in Mt. Liuhuang, Yingde, Guangdong Province. 1957. doi: https://doi. org/10.12063/data.C.2018.NGA11926.T1.80.1.

21. Thirteenth Sino-Soviet Cooperation Brigade. Series of geological maps of the Kashi-Akesu region of Southern Mt. Tianshan, Xinjiang (1). 1957. doi: https://doi.org/10.12063/data.A.NGA13916.T1.5.1.

22. Thirteenth Sino-Soviet Cooperation Brigade. Series of geological maps of the Kashi-Akesu region of Southern Mt. Tianshan, Xinjiang (2).1957. doi: https://doi.org/10.12063/data.A.2018. NGA13916.T1.6.1.

23. First Division of the $701^{\text {st }}$ Team of the Xinjiang Nonferrous Metals Corporation of the Ministry of Metallurgical Industry. Schematic drilling diagram. 1958. doi: https://doi.org/10.12063/data.O.2018. NGA2054.Z1.14.1.

24. Yu Liansheng. Regional hydrological and geological map of the mining areas in the Suyukou, Yugou, and Nansi vicinities of Mt. Helan Mountain. 1958. doi: https://doi.org/10.12063/data.D.2018. NGA16319.T1.37.1.

25. Suqian Squadron of Huaiyin Survey Brigade, Jiangsu Province. Mineral geology report (cover). 1958. doi: https://doi.org/10.12063/ data.O.2018.NGA21855.F1.23.1.

26. Du Zhenfang, Hu Qiangsheng. Cover of the report on mineral exploration in Liancheng County. 1959. doi: https://doi.org/10.12063/ data.O.2018.NGA17845.Z1.37.1.

27. Wan Shuqiong. Sketches of various polymetallic ore specimens from the Wujiang Mining Area of Leishan. 1959. doi: https://doi. org/10.12063/data.C.2018.NGA21265.T1.21.1.

28. Wan Shuqiong. Sketch of Outcrop G1001 of the Dunan Mining Area of Leishan. 1959. doi: https://doi.org/10.12063/data.C.2018. NGA21265.T1.29.1.
29. Gao Fuping, Cao Fangyun. Sketch of shallow well II/E1 of the leadzinc mining area of Bangou. 1959. doi: https://doi.org/10.12063/ data.C.2018.NGA22141.T1.11.1.

30. The $102^{\text {nd }}$ Inner Mongolia Exploration Brigade, Yinchuan Petroleum Exploration Bureau. Sketches of the interface of $J_{3}$ a and $\mathrm{J}_{2} \mathrm{c}$, among others. 1959. doi: https://doi.org/10.12063/data.O.2018. NGA21042.Z1.31.1.

31. Huang Jiqing, Zhao Qinglin, Xiao Xuchang, Jiang Chunfa, Ren Jishun, Cui Shude, Xie Douke. Geotectonic map of the People's Republic of China. Beijing, Geological Publishing House, 1960

32. Sun Deqin, Tian Ronghe, Li Zhongxue. Geomorphological map of the western Inner Mongolia Plateau (I-I', II-II' geomorphology sections). 1961. doi:https://doi.org/10.12063/data.A.2018. NGA26027.T1.13.1.

33. Qinghai Petroleum Administration Bureau. Quaternary geological map of the Qaidam Basin. 1961. doi: https://doi.org/10.12063/ data.A.2018.NGA28587.T1.5.1.

34. Institute of Geology, Chinese Academy of Sciences. Illustration attached to report on a tectonic fracture system and engineering geological issues of the dam area of the Xinfengjiang River. 1962. doi: https://doi.org/10.12063/data.O.2018.NGA32195.Z1.21.1.

35. Gao Huanzhang, Li Shihe, Wang Xinquan, Hu Zhenzong. Tectonic map of the Xi'an area. Beijing, Geological Research Institute of the Ministry of Geology. 1963. doi: https://doi.org/10.12063/ data.A.2018.NGA37738.T1.1.1.

36. Zeng Qingyong. Comparison of reservoir units of Strata $\mathrm{P}_{1}, \mathrm{P}_{2}$, and $\mathrm{T}_{f}$ in the Chongqing area. 1963. doi: https://doi.org/10.12063/ data.A.2018.NGA36941.T1.4.1.

37. Zhou Zhongmin, Liu Hongwen Kang Deyi, Ma Yijie, Zhuang Weifang. Sketch of Exploration ditch $\mathrm{T}_{\mathrm{Q}} 1$ at the crystal mining area of Miaogou. 1968. doi: https://doi.org/10.12063/data.C.2018. NGA43081.T1.34.1.

38. Ma Shiqiong. Sketch of a geode in a mine block of the Gongli Crystal Mining Area, Luodian County, Guizhou Province. 1964. doi: https://doi.org/10.12063/data.C.2018.NGA38692.T1.23.1.

39. Jiuquan Hydrogeological Station, Hydrogeology and Engineering Geological Team of Gansu Geological Bureau. Geological structure projection diagram of the Yinda Experimental Section of Jiuquan. 1966. doi: https://doi.org/10.12063/data.A.2018.NGA40321. T1.1.1.

40. Tang Yingsu. Geomorphological and geological map of the Houdong mineral deposit in the Wuchuan mercury mining belt, Guizhou Province. 1967. doi: https://doi.org/10.12063/data.C.2018. NGA43997.T1.1.1.

41. Revolutionary Committee of the $135^{\text {th }}$ Brigade of Coalfield Geological Exploration Company, Coal Mining Administration of Sichuan Province. Diagram of coal seam thickness variation of Pit 36 in Lanjiawan. 1968. doi: https://doi.org/10.12063/data.B.2018. NGA43349.Z1.14.1.

42. Revolutionary Committee of the $109^{\text {th }}$ Geological Exploration Brigade, Sichuan Geological Bureau. Profile diagram of Lake Exploration Line. 1968. doi: https://doi.org/10.12063/data.A.2018. NGA42671.T1.8.1.

43. The $235^{\text {th }}$ Metallurgical Exploration Brigade of Hunan Province. Joint contour map for the report of the 1963 general survey on the Qitianling area of Hunan Province. 1970. doi: https://doi. org/10.12063/data.O.2018.NGA43569.Z1.25.1.

44. Quaternary Glaciology Expedition Team of the Institute of Geomechanics. Diagram of the composition and distribution of the diamond deposit in eastern Guizhou Province and western Hunan Province. 1975. doi: https://doi.org/10.12063/data.C.2018. NGA54726.T1.5.1.

45. Sun Yunying. Topographic and geological map of Tongyu Chrome Mine in Zuoquan County, Shanxi Province. 1976. doi: https://doi. org/10.12063/data.C.2018.NGA56419.T1.3.1. 
46. Iron-rich deposit exploration team, Hubei Institute of Metallurgical Geology. Schematic diagram of the intrusion of $T_{1,2}$ and $T_{3}$ in the western section of the Lingxiang rock mass, etc. 1978. doi: https:// doi.org/10.12063/data.A.2018.NGA55440.Z1.11.1.

47. First Comprehensive Geophysical Prospecting Team, Ministry of Geology and Mineral Resources. Hypothetic diagram of the development stage of volcanic subsidence of the Lujiang-Zongyang Volcanic Basin. 1983. doi: https://doi.org/10.12063/data.2018. NGA65065.Z1.33.1.

48. Li Juying. Sectional axonometric drawing of engineering geology of the Fuling Road-Labor Road Overpass Project. 1986. doi: https://doi.org/10.12063/data.D.2018.NGA71539.T1.2.1.

49. Sixth Geological Exploration Team of Qinghai Province. Illustrations and sketches of minerals attached to report on geological turquoise survey at Mt. Duancen, Wulan County, Qinghai Province. 1987. doi: https://doi.org/10.12063/data.O.2018. NGA70786.Z1.52.1.
50. Li Baozhu. Sketch of gallery wall of the No. 3 Pegmatite Vein in Wentouyingzi Minefield, Fuxin County. 1988. doi: https://doi. org/10.12063/data.A.2018.NGA33255.T1.67.1.

51. Fourth Geological Exploration Brigade of the Xinjiang Bureau of Geology and Mineral Resources. Geological joint section of No. 1 Deposit. 1989. doi: https://doi.org/10.12063/data.C.2018. NGA76263.Z1.8.1.

52. Zhou Zhaoxin. Geochemical map of vanadium in the geochemical exploration site of an urban area of Shantou City, Guangdong Province. 1990. doi: https://doi.org/10.12063/data.G.2018. NGA76143.T1.36.1.

53. Xu Guiyin. Engineering geological profile of district planning of Jiaojiang City, Zhejiang Province. 1990. doi: https://doi. org/10.12063/data.D.2018.NGA78758.T1.25.1.

54. Cui Zhenshu. Hydrogeological map of the Qingchengzi region in central Liaoning Province. 1992. doi: https://doi.org/10.12063/ data.D.2018.NGA11275.T1.28.1.

Open Access This chapter is licensed under the terms of the Creative Commons Attribution 4.0 International License (http://creativecommons. org/licenses/by/4.0/), which permits use, sharing, adaptation, distribution and reproduction in any medium or format, as long as you give appropriate credit to the original author(s) and the source, provide a link to the Creative Commons licence and indicate if changes were made.

The images or other third party material in this chapter are included in the chapter's Creative Commons licence, unless indicated otherwise in a credit line to the material. If material is not included in the chapter's Creative Commons licence and your intended use is not permitted by statutory regulation or exceeds the permitted use, you will need to obtain permission directly from the copyright holder. 